\title{
Cipango
}

Cahiers d'études japonaises

$22 \mid 2015$

Du particulier et de l'universel

\section{Des recherches sur la question féminine aux études queer : un tournant épistémologique}

From Women's Studies to Queer Studies: Bending Epistemology

\section{Aline Henninger}

\section{OpenEdition}

1 Journals

\section{Édition électronique}

URL : https://journals.openedition.org/cipango/2784

DOI : $10.4000 /$ cipango.2784

ISSN : 2260-7706

\section{Éditeur}

INALCO

\section{Édition imprimée}

Date de publication : 1 janvier 2015

ISSN : 1164-5857

\section{Référence électronique}

Aline Henninger, «Des recherches sur la question féminine aux études queer : un tournant épistémologique », Cipango [En ligne], 22 | 2015, mis en ligne le 12 février 2019, consulté le 09 avril 2022. URL : http://journals.openedition.org/cipango/2784; DOl : https://doi.org/10.4000/cipango. 2784

\section{(c) (i) (5)}

Cipango est mis à disposition selon les termes de la Licence Creative Commons Attribution - Pas d'Utilisation Commerciale 4.0 International. 


\title{
Des recherches sur la question féminine aux études queer : un tournant épistémologique
}

\author{
From Women's Studies to Queer Studies: \\ Bending Epistemology
}

Aline HenNinger

CEJ, Inalco

La critique mettant en cause l'idée d'une relation naturelle entre sexe, genre et hétérosexualité correspond à la rupture épistémologique qui a donné naissance aux études de genre ${ }^{1}$. Au Japon, la déconstruction des catégories « homme » et «femme » et de la norme sexuelle intervient au début des années 1990 et soumet la réflexion universitaire à l'épreuve d'une complexité nouvelle. Comme les autres disciplines et champs de recherche, cette rupture s'inscrit dans l'histoire plus vaste des sciences sociales et ne peut être dissociée du contexte particulier dans lequel les connaissances sont produites. L'histoire des sciences ayant déjà

1. EHARA Yumiko 江原由美子, Feminizumu ronsō : nanajū nendai kara kyūjū nendai eフェミニズム論争一70年代から90年代へ (Les débats féministes des années 1970 aux années 1990), Tōkyō, Keisō shobō 勁草書房, 1990, p. 150-156. 


\section{CIPANGO}

110 Cahiers d'études japonaises n²2

interrogé les cadres de sa recherche de la vérité ${ }^{2}$, l'épistémologie montre que les connaissances produites n'échappent en aucun cas aux biais heuristiques de leur époque, parmi lesquels le genre, pour les sciences dures comme pour les sciences sociales ${ }^{3}$. Les études de genre démontrent justement en quoi les sciences s'extraient difficilement du déterminisme des sexes, mais elles font également preuve de réflexivité lorsqu'elles expliquent leur propre cadre d'institutionnalisation au sein d'un savoir essentiellement androcentré ${ }^{4}$.

En s'appuyant sur cette perspective, nous essaierons ici de retracer la sociogenèse des études de genre (jendā sutadizu ジェンダー・スタディーズ), des études gaies et lesbiennes (gei/rezubian sutadizu ゲイ/レズビアン・スタディーズ ${ }^{5}$ ), ainsi que des études queer (kuia sutadizuクイア・スタディーズ6) au Japon. Précisons d'emblée les caractéristiques de ces nouveaux domaines : les « études de genre » s'incarnent dans un ensemble d'ouvrages pluridisciplinaires qui utilisent le concept de « genre » (jendāジェンダー) qu'on peut définir comme le système qui produit une bipartition hiérarchisée entre les sexes (hommes/femmes), et entre les valeurs et représentations qui leur sont associées (masculin-féminin). Les études de genre s'institutionnalisent à partir des années 1980 aux États-Unis, et dans les années 1990 dans d'autres pays, dont le Japon. Elles donnent naissance

2. Georges Canguilhem, Études d'histoire et de philosophie des sciences, Paris, Vrin, 1968 , p. 9-23.

3. Ludwig FleCK, Genèse et développement d'un fait scientifique, Paris, Flammarion, collection «Champs, science », 2008. La préface d'Ilana Löwy, historienne de la médecine, est révélatrice de la construction sociale des sciences biomédicales, qui n'échappe pas non plus aux déterminismes du genre.

4. Laure Bereni, Sébastien Chauvin, Alexandre Jaunait, Anne Revillard, Introduction aux études de genre, Bruxelles, De Boeck, collection « Ouvertures politiques », 2012 (deuxième édition), p. 10-16.

5. Le terme français et son orthographe (études gaies et lesbiennes) semble désormais fixé. On peut aussi distinguer les études gaies (gei sutadizu ゲイ・スタディーズ) et les études lesbiennes (rezubian sutadizu レズビアン・スタディーズ), les deux termes existant aussi en japonais.

6. On parle aussi de 《lecture queer » (kuia no shiten karaクイアの視点から) ou de « théorie queer» (kuia riron クイア理論). 
aux études gaies et lesbiennes, qui dénaturalisent les concepts de masculinité et féminité, et s'interrogent sur la relation entre hétérosexualité, homosexualité, bisexualité et transsexualité. Ces catégories sont regroupées sous l'acronyme LGBT (Lesbien, gai, bi et trans ${ }^{7}$, de l'anglais Lesbian Gay Bisexual and Transgender), qui sert à qualifier les sexualités et pratiques non hétérosexuelles, étudiées dans leur ensemble au sein des « études LGBT» (LGBT studies en anglais). Les « études queer $\gg$ quant à elles, nées dans les années 1990, veulent s'extraire précisément de ces catégories (hommes/femmes et LGBT), pour souligner que les identités de genre ne sont pas aussi compartimentées et que, de la même manière, les sexualités ne peuvent pas se définir de façon distincte face à l'hétérosexualité dominante, puisqu'elles ont toutes leurs contradictions et incohérences.

On montrera que ces travaux s'inscrivent dans une histoire intellectuelle étroitement liée à l'histoire sociale japonaise, et qu'ils participent à la remise en cause globale du savoir à partir des années 1960. Il convient d'examiner comment se nouent des liens entre les études de genre (gender studies), les études gaies et lesbiennes (gay and lesbian studies) et enfin les études queer (queer studies) nordaméricaines : après réception et appropriation des concepts, tant les militants féministes et LGBT que les universitaires japonais vont développer ces outils pour penser dans leur langue et s'interroger spécifiquement sur les thèmes propres à leur pays. Retracer cette épistémologie du placard ${ }^{8}$ japonais peut se faire en déterminant la généalogie des différents concepts, mais également en s'attachant à comprendre comment ces sources de savoirs nouveaux ont pu se définir et s'établir comme un champ académique. Indissociablement, de la question féminine aux études queer, sinue le chemin autonome des féminismes japonais, dans un cadre

7. Le terme « trans » peut ici désigner à la fois les transsexuels (qui revendiquent leur appartenance à un sexe avec généralement un recours à la chirurgie) et les transgenres (qui n'ont pas recours à la chirurgie et affirment leur identité « trans » en tant que telle, et non l'appartenance au sexe masculin ou féminin).

8. Le terme est emprunté à Eve Kosofsky Sedgwick dont l'ouvrage Epistemology of the Closet (traduit en français en 2008, sous le titre de Epistémologie du placard), paru en 1990 aux États-Unis, est rapidement devenu un classique de la théorie queer. Eve Kosofsky Sedgwick, Epistemology of the Closet, University of California Press, Oakland, 1990, 258 p. 


\section{CIPANGO}

112 Cahiers d'études japonaises n²2

militant qui ne cesse de se modifier, ce qui implique un rapport complexe et alternatif entre théories, pratiques quotidiennes et activisme féministe.

Pour atteindre notre objectif, nous nous attarderons sur différentes ruptures épistémologiques, en les articulant au cadre historique dans lequel évoluent structures et mouvements sociaux. Aux premières heures du féminisme japonais se constitue un savoir relatif au statut de la femme : les recherches sur la « question féminine », qui posent des questions sur le suffrage féminin, l'éducation des filles, l'écriture féminine ${ }^{9}$, la maternité, la famille, la prostitution ${ }^{10}$, l'avortement ${ }^{11}$ en particulier. On retrouve bien plus tard les thèmes de ces réflexions dans les années 1970 au sein des « études féminines ». Les « études de genre », prenant place dans les années 1990, bouleversent cette tradition où seule la condition féminine était examinée : ce sont désormais les rapports entre hommes et femmes qui sont analysés. La sexualité n'échappe pas à cette analyse, et sa dénaturalisation donnera lieu aux nouveaux champs de recherches que sont les « études gaies et lesbiennes », puis les «études queer ».

\section{Une première vague féministe : les recherches sur la question féminine}

Le champ de recherche que forment les gender studies (jendā sutadīzu ジェン ダー・スタディーズ) - ou plus communément en japonais les « études de genre » (jendāgaku ジェンダー学 ${ }^{12}$ ) - s'est développé depuis les années 1990. Cette première assise académique ne doit toutefois pas éclipser les précédentes réflexions sur le statut de la femme. Les « recherches sur la question féminine »

9. ŌTA Tomomi, «Devenir écrivain/devenir femme/devenir soi : l'écriture et l'amour dans les textes littéraires de Seitô », Japon Pluriel 9, Arles, éditions Philippe Picquier, 2014, p. 117-126.

10. Marion SAUCier, « Le débat dans Seitô entre Itô Noe et Yamakawa [Aoyama] Kikue sur la prostitution, ou la confrontation de deux féministes », Japon Pluriel 10, Arles, éditions Philippe Picquier, 2014, p. 239-249.

11. Isabelle Konuma, « L'avortement dans Seitô : la formation de l'espace décisionnel des femmes », Japon Pluriel 10, Arles, éditions Philippe Picquier, 2014, p. 213-228.

12. Si les deux expressions existent, le terme d' « études de genre », avec le suffixe -gaku (jendāgaku ジェンダー学), est bien plus courant. 
(fujin mondai kenkyū 婦人問題研究) et les 《études féminines 》 (joseigaku 女 性学) impliquent en effet des objets d'études et une historicité différente. On tentera de retracer sur plus d'un siècle les mouvements et la pensée féministes au Japon afin de comprendre la systématisation d'un savoir sur les rapports de sexe.

À partir des années 1870, la famille japonaise se modifie progressivement, notamment avec les bouleversements sociétaux et légaux qui colorent le dernier tiers de l'ère Meiji ${ }^{13}$. Le discours sur le rôle idéal des femmes comme «bonnes épouses et mère avisées »(ryōsai kenbo 良妻賢母) n’empêche pas plusieurs femmes d'avoir une activité publique ou littéraire ${ }^{14}$. On retient généralement pour cette période la figure de Kishida Toshiko 岸田俊子 (1863-1901), qui prend la plume dans les années 1880 et dénonce le peu de libertés accordées aux femmes ${ }^{15}$. Deux décennies après, à la toute fin de l'ère Meiji et durant l'ère Taishō (1912-1926), plusieurs intellectuels et militants socialistes s'engagent en faveur de l'émancipation des femmes. Ce sont également des femmes qui fondent, au sein des cercles socialistes, des groupes d'études sur les questions féminines ${ }^{16}$. La fin des années 1900 et les années 1910 voient se développer également des cercles littéraires où les auteurs femmes expriment leurs talents ${ }^{17}$. La revue Les bas-bleus (Seitō 青鞜, 1911-1916) apparaît emblématique de ce mouvement féminin politique et littéraire ${ }^{18}$. C'est dans ce contexte que se forme l'expression fujin mondai 婦人問題, la 《question féminine ». Le mot fujin est choisi pour plusieurs raisons : il n'a pas de connotation vulgaire comme onna, la

13. Christian Galan et Emmanuel Lozerand (dir.), La Famille japonaise moderne (1868-1926). Discours et débats, Arles, éditions Philippe Picquier, 2011, 666 p.

14. Claire Dodane, «Femmes écrivains des années 1910 : amour, féminisme et indépendance », Japon Pluriel 9, Arles, éditions Philippe Picquier, 2014, p. 137-144.

15. Christine Lévy (dir.), Genre et modernité au Japon. La revue Seitô et la femmen nouvelle, Rennes, Presses universitaires de Rennes, 2014, p. 22-24.

16. Ibid., p. 13-14.

17. Claire Dodane, « L'écriture féminine dans le Japon moderne », in Christian Galan et Emmanuel Lozerand (dir.), op. cit., 2011, p. 431-443.

18. Christine LÉvy (dir.), op. cit., 2014, p. 13-28. 


\section{CIPANGO}

114 Cahiers d'études japonaises $n^{\circ} 22$

« fille », et par extension la « fille publique ${ }^{19}$ ». En outre ce terme (déjà existant) n'a pas de correspondant masculin, contrairement à jose $i^{20}$. Il valorise la femme et la distingue de l'homme. Il apparaît par exemple dans le nom de la revue féministe et socialiste Sekai fujin (Femmes du monde) créée en 1907. Le mot fujin prend alors sa connotation politique durant cette période, les années 1900 et 1910, pour acquérir la nuance suivante : la femme dans le sens d'une personne qui doit obtenir droits et devoirs civiques de la même façon que les citoyens masculins ${ }^{21}$. La question féminine s'avère ainsi indissociable du mouvement socialiste ${ }^{22}$. La traduction ici adoptée pour fujin mondai 婦人問題, 《question féminine » (voire «question des femmes »), correspond à l'expression utilisée dès la fin du $\mathrm{XIX}^{\mathrm{e}}$ siècle en Europe au sein des cercles socialistes et communistes ${ }^{23}$.

Ce terme de « question féminine » donne ensuite naissance dans les années 1920 à celui de « recherches sur la question féminine » (fujin mondai kenkyū 婦人問題研究 $\left.{ }^{24}\right)$. Cette expression désigne donc à partir de l'ère Taishō l'ensemble des écrits relatifs aux femmes. Le terme de « recherche » (kenkyū 研 究), qui ne reprend pas le suffixe -gaku 学 (-logie), utilisé pour le nom d'une discipline, n'implique pas un domaine académique, ou un protocole scientifique

19. Fujimura-Fanselow Kumiko, Kameda Atsuko (eds), Japanese Women. New Feminist Perspectives on the Past, Present and Future, New York, The Feminist Press, 1995, p. 156.

20. Le terme fujin (婦人) n'a pas d'équivalent masculin (on pourrait imaginer danjin 男人). Par contraste, les autres termes ont toujours un composé symétrique fondé sur l'opposition entre les caractères onna/otoko 女/男: josei/dansei 女性/男性, joshi/danshi 女子/男子 et onna no kolotoko no ko 女の子/男の子. Ainsi, le terme fujin marque la spécificité de la femme face au masculin, pensé comme universel et non désigné.

21. Christine LÉvy (dir.), op. cit., 2014, p. 13.

22. Les textes d'auteurs ou journalistes se revendiquant socialistes, comme par exemple Kōtoku Shūsui (1871-1911) ou Fukuda Hideko (1865-1927), illustrent le lien entre socialisme et féminisme.

23. De façon similaire, on parle de the women question en anglais et die Frauenfrage en allemand.

24. NAGAI Tōru 永井亨, Fujin mondai kenkyū 婦人問題研究 (Recherches sur la question féminine), Tōkyō, Iwanami shoten, 1925, 544 p. 
défini, mais simplement un objet d'étude : la condition féminine. Cette catégorie de « recherches sur la question féminine » reste néanmoins floue puisqu'elle regroupe tout sujet qui concerne les femmes, sans réflexion sur la spécificité de leurs problèmes. De nombreux écrits peuvent ainsi être catégorisés comme tels. Dans son emploi actuel, le terme renvoie spécifiquement aux écrits de l'ère Taishō et du début de l'ère Shōwa. De façon plus large, on peut considérer que ces « recherches » couvrent une période plus large, qui s'étend des années 1880 aux années 1960 : de l'apparition d'une prise de parole féminine et des premières revendications féministes jusqu'à l'apparition de la deuxième vague féministe des années 1960.

Les recherches sur la question féminine semblent largement orientées par l'approche marxiste : la solution au problème des rapports hommes/femmes apparaît très souvent sous l'angle d'une domination de classe sociale et d'un rapport aliénant au travail. Ce biais ne tient pas compte de la disparité des conditions féminines d'une classe à l'autre, et de la domination masculine toutes classes confondues ${ }^{25}$. Malgré une accumulation nouvelle de connaissances sur la condition féminine, aucune vision d'ensemble ni interdisciplinarité ne sont avancées pour permettre une compréhension plus poussée des déterminants de la domination masculine ${ }^{26}$. Inscrites dans une perspective réformiste, ces recherches s'intéressent en particulier au suffrage féminin, à l'éducation, aux conditions de travail, à la contraception, à la protection de la maternité, à la définition d'un statut conjugal, ou encore à la prostitution. Ces débats constituent les revendications de la « première vague du féminisme japonais » (daiippa feminizumu 第一波フェ ミニズム), caractérisée avant tout par la lutte pour l'obtention des droits de vote et d'éligibilité, obtenus en $1946^{27}$.

Les protagonistes sont des femmes et des hommes féministes, le plus souvent auteurs, traducteurs, romanciers, journalistes et essayistes, progressistes ou

25. Vera Mackie, Feminism in Modern Japan. Citizenship, Embodiment and Sexuality, Cambridge, Cambridge University Press, 2003, p. 162.

26. Fujimura-Fanselow Kumiko, Kameda Atsuko, op. cit., 1995, pp. 156-157.

27. Kimura Ryōko 木村涼子 (dir.), Jendā to kyōiku ジェンダーと教育 (Genre et éducation), Tōkyō, Nihon tosho sentā 日本図書センター, 2009, p. 3. 


\section{CIPANGO}

116 Cahiers d'études japonaises n²2

proches des cercles socialistes, comme Sakai Toshihiko 堺利彦 (1871-1933), Hiratsuka Raichō 平塚らいてう (1886-1971), Takamure Itsue 高群逸 枝 (1894-1964), Yamakawa Kikue 山川菊栄 (1890-1980), Oku Mumeo 奥む めお (1895-1997), Itō Noe 伊藤野枝 (1895-1923), Katō Shizue 加藤シジ 工 (1897-2000), ou Miyamoto Yuriko 宮本百合子 (1899-1951). Les publications d'articles dans les journaux nationaux et militants sont nombreuses, et les revues féminines, comme par exemple Le monde des étudiantes (Jogaku sekai 女学世 界, 1901-1926), Le monde féminin (Fujinkai 婦人界, 1902-1904), Le monde desfermmes (Fujin sekai 婦人世界, 1905-1933), Le monde féminin (Fujokai 婦女 界, 1910-1952), L'ami des ménagères (Shufu no tomo 主婦の友, fondée en 1917) ou Débats féminins (Fujin kōron 婦人公論, fondée en 1916), contribuent à cette dynamique. Plusieurs auteurs femmes se distinguent alors ${ }^{28}$. Les débats de la revue féministe Les bas-bleus, extrêmement riches et variés, illustrent l'ensemble des réflexions portant sur les droits des femmes à l'époque, tout en présentant les situations d'autres pays ${ }^{29}$. On note également quelques tentatives d'écrire une histoire redonnant sa place aux femmes, comme la traduction de l'ouvrage de Charles Letourneau (L'Évolution du mariage et de la famille) qu'établit Ōsugi Sakae en 1916, L'évolution des relations hommes-femmes (Danjo kankei no shinka 男女関係の進化), ou bien en 1920 une Histoire de la lutte entre les hommes et femmes (Danjo sōtōshi 男女争闘史), puis en 1922 Le développement des relations entre les hommes et femmes (Danjo kankei no hattatsu 男女関係の発 達) publiés par Sakai Toshihiko. Les recherches sur la question féminine brassent toutes les interrogations de l'époque et défrichent des pans entiers de plusieurs disciplines. Elles ne correspondent donc pas à un savoir spécifique, mais plutôt à une tentative de rassembler des connaissances. Des femmes prennent la plume pour parler de la condition féminine, puis des auteurs (hommes et femmes) s'interrogent sur la condition des femmes, et dénoncent certaines inégalités de traitement : telles sont les caractéristiques de ces recherches, qui s'inscrivent

28. Claire Dodane, op. cit., 2011, p. 431-443.

29. Christine Lévy (dir.), « Naissance d'une revue féministe au Japon : Seitō (1911-1916) », Ebisu, n 48, Tōkyō, Maison franco-japonaise, automne-hiver 2012. 
parfaitement au sein de l'effervescence intellectuelle et politique de l'ère Taishō et du début de l'ère Shōwa.

\section{La deuxième vague féministe : les études féminines}

Les années 1946 et 1947 concrétisent les vœux de la première vague féministe et font miroiter une égalité des sexes obtenue grâce à l'appareil juridique. En effet, la nouvelle Constitution inscrit l'égalité des hommes et des femmes parmi ses principes, le Code civil définit en conséquence le mariage et le divorce, et la scolarité publique obligatoire est désormais mixte. Les principales figures militantes des années 1900-1940 se font discrètes après l'obtention de ces droits, ou disparaissent par un effet de génération ${ }^{30}$. Organisées à la fin des années 1940, de nombreuses petites associations de femmes, présentes sur tout le territoire japonais, donnent au féminisme japonais une nouvelle ampleur et un ancrage local ${ }^{31}$. Ces associations permettent de collecter des documents pour rédiger des textes sur l'histoire des femmes. À la toute fin des années 1960 se constitue le « mouvement de libération ${ }^{32}$ des femmes » (ou üman ribu ウーマン・リブ, de l'anglais Women Liberation), qui correspond à ce qu'on nomme désormais la « deuxième vague féministe ${ }^{33} »$. Porté cette fois-ci uniquement par des femmes qui se positionnent contre la domination masculine, calqué sur les revendications du Women Liberation aux États-Unis, ce féminisme n'a plus rien à voir avec l'ancienne bataille pour les droits

30. L'histoire des femmes pendant la guerre (notamment la création, en 1942, puis son démantèlement, en 1945, de l'association des femmes de l'Empire japonais, Dainihon fujin-kai 大日本婦人会) joue également un rôle dans la recomposition des mouvements féministes à la sortie de la guerre.

31. Gayle Curtis Anderson, Women's History and Local Community in Postwar Japan, London, New York, Routledge, 2010, p. 9.

32. Le japonais $k a i h \bar{o}$ 解放 (émancipation) cède la place à un anglicisme, ribu リブ, ce qui est révélateur du changement d'époque et de l'influence des mouvements féministes nord-américains.

33. KimURA Ryōko (dir.), op. cit., 2009, p. 3-5. 


\section{CIPANGO}

118 Cahiers d'études japonaises n²2

électoraux : le travail, l'autonomie ${ }^{34}$ et l'épanouissement sexuel forment le cœur des principales revendications. Ce mouvement de libération naît à Tōkyō, mais divers groupes se forment en dehors de la capitale, ce qui lui donne une certaine ampleur $^{35}$. Si les débats entre historiens et sociologues japonais sur la place du mouvement de libération (üman ribu) ne sont pas tranchés, on peut néanmoins retenir l'idée que celui-ci ne constitue pas un bloc monolithique soudé autour d'idées arrêtées : on constate par exemple des dissensions entre femmes socialistes et conservatrices, ou hétérosexuelles et lesbiennes ${ }^{36}$. L'ensemble des associations féministes qui se forment dans cette mouvance au cours des années 1970 et 1980, ancrées dans un réseau local, portent ainsi des visions féministes très variées ${ }^{37}$. Il semble par ailleurs qu' une importante partie des femmes au foyer ne comprenaient pas le but de ce mouvement, ni ne voulaient y participer.

Cette deuxième vague féministe trouve un prolongement dans les différentes mesures des Nations unies pour la cause des femmes ${ }^{38}$, ainsi que dans le développement des études féminines aux États-Unis, au Canada et en Europe. Au milieu des années 1970, ce contexte marque l'établissement d'un nouveau type de savoir académique au Japon : les «études féminines » (joseigaku $\left.{ }^{39}\right)$. Le terme

34. L'ouvrage de Betty Friedan, The Feminine Mystique (1963), a un impact très fort au Japon lors de sa traduction (Atarashii josei no sōzo 新しい女性の創造 [La création d'une femme nouvelle]) en 1965, par Miura Fumiko, aux éditions Daiwa shobō. La vacuité de la vie d'une parfaite femme au foyer y est dénoncée : de nombreuses Japonaises se retrouvent dans cette description.

35. Ehara Yumiko, Feminizumu no paradokkusu. Teichaku ni yoru kakusan フェミニズ ムのパラドックス一定着による拡散 (Les paradoxes du féminisme : sa plasticité au gré de sa définition), Tōkyō, Keisō shobō, 2000, p. 15-17.

36. Vera MACKiE, op. cit., 2003, p. 159-163.

37. Laura Dales, Feminist Movements in Contemporary Japan, London, New York, Routledge, 2009, pp. 31-37.

38. En novembre 1975 a lieu la conférence pour l'année internationale de la femme, puis en 1979 est adoptée la convention sur l'élimination de toutes les formes de discrimination à l'égard des femmes, et enfin la décennie 1975-1985 est proclamée Décennie pour la femme.

39. Fujimura-Fanselow Kumiko, Kameda Atsuko, op. cit., 1995, p. 158. 
« recherches sur la question féminine » (fujin mondai kenkyū) est abandonné au profit d'une traduction de l'anglais womens' studies $^{40}$ : en se débarrassant de la connotation socialiste, les universitaires veulent ériger un nouveau champ de recherche, ce que marque le suffixe -gaku. La traduction en français pose problème : on parle souvent d' «études féminines », à défaut de pouvoir employer le terme de « gynécologie », ou des néologismes comme « féminalogie » ou « gynologie ». Au Japon, les premiers enseignements universitaires d'études féminines apparaissent en 1973 et se multiplient dès la fin de la décennie ${ }^{41}$. Des cursus spécifiques se mettent en place ultérieurement, lorsque le nombre de professeurs spécialistes, mais aussi la demande de cours, augmentent ${ }^{42}$. L'ensemble de ces éléments détermine le contexte dans lequel essaiment ces études, qui forment un champ de recherche ouvert à toutes les disciplines ${ }^{43}$. Une nouvelle génération de chercheurs et chercheuses apparaît, qui s'intéressent aux études féminines par

40. Le génitif anglais et le terme japonais laissent un flou que la langue française ne peut garder. Si l'on adopte ici pour traduire joseigaku le terme « études féminines » (comme l'a fait en 1974 le département de l'université Paris-8, alors à Vincennes, premier établissement à adopter les axes de recherche des womens'studies), il est aussi possible de parler d' «études féministes » ou encore d' « études sur les femmes ».

41. Kokuryo Sonoko, « L'installation de cours d'études féminines et de centres de documentation sur les femmes au Japon », BIEF, Centre d'études féminines de l'université de Provence, Aix-en-Provence, nº 16, mai 1985, p. 114-120.

42. Le Centre pour la recherche en études féminines de l'université Ochanomizu, fondé en 1986, devient en 1996 le Centre d'études de genre. L'université Ochanomizu développe des enseignements entièrement dédiés aux études féminines, puis au genre : un programme doctoral créé en 1993 au sein du département d'études féminines, en 1997 un master « Genre et développement », puis en 2005 un programme doctoral pluridisciplinaire pour les études de genre.

43. Ehara Yumiko, «Le développement théorique des études sur les femmes et le genre dans le Japon contemporain des années 1970 à nos jours », in SociéTÉ FRANCOJAPONAISE DES ÉTUDES SUR LES FEMMES 日仏女性研究学会 (dir.), Actes des Recherches collectives franco-japonaises: Pour la comparaison franco-japonaise des études sur les fermmes. Sur la nécessité des nouvelles méthodologies comparatives 日仏共同研究報告 書 女性研究における日仏比較 新しい比較方法論の必要性をめぐって, Société franco-japonaise des études sur les femmes 日仏女性研究学会, 2002, p. 40. 


\section{CIPANGO}

120 Cahiers d'études japonaises n²2

convictions personnelles, curiosité intellectuelle ou opportunité de carrière au sein de nouveaux programmes. Né(e)s dans l'immédiat après-guerre, devenu(e) s adultes dans les années 1970, avant tout historien(ne)s ou sociologues ${ }^{44}$, ce sont principalement des femmes, comme Ueno Chizuko 上野千鶴子 (née en 1948), Tachi Kaoru 舘かおる (née en 1948), Ehara Yumiko 江原由美子 (née en 1952), Ogino Miho 荻野美穗 (née en 1945), ou Takemura Kazuko 竹村和 子 (1954-2011). De nouvelles sociétés savantes sont créées : Société de recherches sur l'histoire des femmes (Joseishi sōgō kenkyūkai 女性史総合研究会), fondée par Wakita Haruko 脇田晴子 en $1977^{45}$, Société internationale de recherches sur les femmes (Kokusai josei gakkai 国際女性学会) en 1978, Cercle de recherches sur les femmes (Joseigaku kenkyūkai 女性学研究会) et Société japonaise de recherches sur les femmes (Nihon joshi gakkai 日本女性学会) en 1979. On voit ainsi que les études féminines, nées au milieu des années 1970, s'établissent assez rapidement et de façon solide à l'université dans les années suivantes ${ }^{46}$.

Le contenu des études féminines est novateur : les universitaires ne se contentent plus de décrire la situation des femmes, elles interrogent les rapports sociaux entre les sexes. La charge critique prend le pas sur l'aspect descriptif : la perspective féministe sert à démontrer les ressorts des inégalités entre les sexes. Le choix même des mots implique une revendication féministe : le terme josei 女 性, d'usage courant depuis l'après-guerre, est préféré au terme onna 女, plutôt péjoratif. En effet, le mot onna comporte une connotation sexuelle forte, et souvent négative ${ }^{47}$. Par glissement, le terme devient synonyme de « maîtresse » ou de « prostituée », et on le retrouve dans plusieurs expressions à caractère sexuel.

44. Ishida Hitoshi, Mark McLelland, Murakami Takanori, “The Origins of Queer Studies in Postwar Japan”, in Mark McLelland, Romit Dasgupta (eds), Genders, Transgenders and Sexualities in Japan, London, Routledge Curzon, 2005, p. 33.

45. Site de la Société de recherches sur l'histoire des femmes, disponible sous http://www.geocities.jp/joseishi_sougou/index.html (consulté le $1^{\text {er }}$ mai 2013).

46. Ehara Yumiko, op. cit., 2002, p. 17-20.

47. On peut tout à fait comparer avec le mot « fille » en français, notamment avec l'article indéfini « une fille », par extension « une fille de rien », ou « une fille publique » ou « une fille de joie ». 
Le sinogramme qui sert à transcrire onna 女 se retrouve également dans des termes comme memeshii 
122 Cahiers d'études japonaises n²2

privée. Ces féministes alimentent la «polémique sur le travail domestique ${ }^{53}$ »

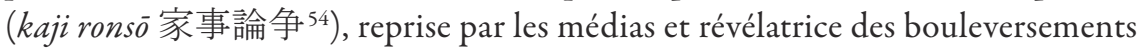
de l'emploi féminin de l'époque. Dans ce contexte, la figure centrale de la mère au foyer (sengyō shufu 専業主婦) fait partie de l'histoire des mouvements féministes japonais et de ce que l'on nomme aujourd'hui la polémique sur les femmes au foyer (shufu ronsō 主婦論争) entre les années 1950 et 1970.

Les études féminines reflètent ainsi la diversité de la pensée féministe, que l'on retrouve à travers la multiplicité des thèmes des écrits de l'époque. Les divers groupes féministes ne développent ni les mêmes arguments ni les mêmes activités. Cette pluralité n'empêche pas, au contraire, la publication d'articles et d'ouvrages qui cherchent à établir une histoire des femmes (joseishi 女性史). Parmi d'autres, on retiendra Histoire des femmes de l'ère Meiji ${ }^{55}$, les cinq volumes de l' Histoire des femmes japonaises ${ }^{56}$, et Sandakan, bordel numéro $8^{57}$. Les sciences humaines et sociales sont relues sous un angle féministe : des femmes universitaires deviennent auteurs d'une histoire féminine. Elles revendiquent cette parole, et l'autonomie

53. Ce débat a lieu de la fin des années 1970 au début des années 1980. Les féministes essentialistes voient le foyer comme un espace potentiel d'émancipation de la femme mariée, libre de gérer sa maison comme elle l'entend, alors que les féministes matérialistes soulignent la valeur inférieure accordée aux travaux domestiques, qui rend invisible la femme comme acteur économique et la dévalorise comme acteur social.

54. IDA Kumiko 伊田久美子, «“Baton o watasu” to iu koto. Marukusu shugi feminizumu kara “ohitorisama” e »「ハトンを渡す」ということ一マルクス主義フェミニズ ムから「おひとりさま」へ(《Passer le relais » : du féminisme matérialiste au livre La Solitude du troisième âge), Gendai shisō 現代思想 (Revue de la pensée d'aujourd'hui), vol. 17, n 39, Tōkyō, décembre 2011, p. 89-92.

55. Il s'agit de Meiji joseishi 明治女性史 (Histoire des femmes de l'ère Meiji), de Murakami Nobuhiko 村上信彦, dont la publication s'étale de 1970 à 1973.

56. Publiés en 1982 à l'initiative de la Société de recherches sur l'histoire des femmes (Joseishi sōgō kenkyūkai), les cinq volumes intitulés Nihon joseishi 日本女性史, parus aux presses de l'université de Tōkyō, demeurent une référence.

57. Publié en 1972, le livre Sandakan hachiban shōkanサンダカン八番娼館 (Sandakan, le bordel numéro 8) de Yamazaki Tomoko 山崎朋子 est un des premiers livres à parler de la prostitution en Asie du Sud-Est au début du $\mathrm{Xx}^{\mathrm{e}}$ siècle et de la prostitution militaire organisée par le Japon lors de la guerre (1931-1945). 
qui en découle : ce ne sont plus uniquement les hommes qui parlent à la place des femmes. Cette démarche se veut un moyen de s'émanciper de la domination masculine sur la fabrication des savoirs.

\section{Du concept de « genre » aux « études de genre »}

Comment s'effectue, entre les années 1980 et 1990, le passage des « études féminines » aux « études de genre ${ }^{58} »$ ? En 1992, Ogino Miho traduit "Gender: A Useful Category of Historical Analysis" de Joan Scott, ce qui provoque au Japon un remous intellectuel semblable à celui survenu en 1986 lors de la parution initiale de l'article dans la revue American History Review. Scott y bouscule l'approche marxiste alors dominante pour laquelle les rapports hommes-femmes ne reposent que sur les catégories de classes sociales antagonistes, historiquement constituées par les rapports de production. Elle déconstruit la catégorie « femme », alors vue comme un élément homogène, pour définir le genre comme « une façon première de signifier les rapports de pouvoir », en incluant sexe, classe et race. L'opposition tranchée entre sexe (biologique) et genre (rôle social), liée à celle de nature/culture, se fissure ${ }^{59}$ : le sexe comme le genre relèvent d'une construction sociale ${ }^{60}$. En ce sens, le concept de genre s'oppose à une vision naturaliste des sexes qui attribue des caractéristiques aux hommes et aux femmes en fonction de leurs différences biologiques et permet de mettre en évidence le processus relationnel, qui marque les dynamiques d'opposition entre les femmes et les hommes, le féminin et le masculin. Ogino reprend cette analyse et défend alors l'introduction du concept

58. Ehara Yumiko, op. cit., 2002, p. 27-30.

59. Laure Bereni, Sébastien Chauvin, Alexandre Jaunait, Anne Revillard, op. cit., 2012, p. 16-17.

60. Des travaux d'anthropologie ou de sociologie qui mettent en évidence le caractère social des rôles sexués existent déjà, les plus connus étant ceux de Margaret Mead (1901-1978), de Gayle Rubin (1949-) ou d'Ann Oakley (1944-), ainsi que l'essai de Simone de Beauvoir (1908-1986), Le Deuxième sexe. Les travaux des psychologues et psychiatres comme John Money (1921-2006) ou Robert Stoller (1925-1992) définissent également le genre par opposition au sexe. Ces travaux en restent à penser une opposition entre sexe physique (biologiquement déterminé) et sexe social (le genre). 
124 Cahiers d'études japonaises $n^{\circ} 22$

de « genre » (jendā ジェンダー) afin d'interroger la catégorie du masculin (en particulier les auteurs/détenteurs du savoir), en relation avec d'autres facteurs sociaux (classe, âge, éducation), pour jeter un regard nouveau sur l'ensemble des disciplines japonaises.

On lui reproche d'escamoter la charge subversive que permet une approche strictement féminine ${ }^{61}$, ce que regrettent par exemple Tachi Kaoru ou Itō Yasuko 伊 藤康子 qui ont beaucoup œuvré à la diffusion des études féminines ${ }^{62}$. En outre, certains chercheurs japonais s'interrogent sur la pertinence d'un concept perçu comme propre au féminisme européen et nord-américain. Comme aux États-Unis ou en Europe, l'outil conceptuel « genre », du fait de sa complexité, n'a pas manqué de susciter des débats et des dissensions au sein du monde académique et une certaine incompréhension du grand public ${ }^{63}$. Le concept de genre s'est développé sur le terreau des études féminines reflétant elles-mêmes les différents courants du féminisme (marxiste, radical, écologique, libéral) qui s'incarnent dans différents mouvements sociaux. En conséquence, nombreuses sont les personnes qui ont utilisé ce concept de genre de la fin des années 1980 jusqu'à aujourd'hui ${ }^{64}$.

Après plusieurs années, le « genre » est validé comme outil théorique : on lui reconnaît une meilleure précision heuristique. En effet, le genre permet d'analyser plusieurs objets de recherche et d'articuler de façon pertinente les catégories de classe et de race pour théoriser les structures globales de la société ${ }^{65}$. La puissance théorique de cet outil souligne ainsi les limites de l'utilisation d'une focale trop

61. Contrairement aux études féminines, le genre a renforcé la barrière entre la sphère féministe militante et la sphère universitaire japonaise, la première percevant le genre comme un outil de plus pour l'analyse des disciplines traditionnelles (et donc fondées sur un savoir masculin), et non comme une remise en cause féministe de la fabrication masculine des savoirs.

62. Andrea Germer, op. cit., 2003, p. 7.

63. Ето Mikiko, “'Gender Problems in Japanese Politics': A Dispute over a SocioCultural Change towards Increasing Equality”, Japanese Journal of Political Science, $\mathrm{n}^{\circ} 17$, vol. 3, 2016, pp. 367-368.

64. À titre d'exemple : Société franco-Japonaise des Études SUR Les FEMMES (dir.), op. cit., 2002.

65. Ehara Yumiko, op. cit., 2002, p. 42. 
exclusive, comme dans les études féminines qui continuent néanmoins de se développer ${ }^{66}$.

Les « études de genre » (jendāgaku ジェンダー学) désignent ainsi toute une série de recherches sur les mécanismes genrés, recherches qui s'institutionnalisent à l'université japonaise dans la décennie 1990. Portées notamment par des universitaires, hommes et femmes, plus enclins à prendre leurs distances par rapport aux mouvements féministes, elles trouvent rapidement une place au sein des curricula de licence et de master ; le terme même de jendā ジェンダー se diffuse, y compris dans les médias ${ }^{67}$. De la même façon que furent fondés dans les années 1970 les centres d'études féminines, des institutions dédiées aux études de genre apparaissent : en 1997 est créée l'Association japonaise des études de genre (Nihon jendā gakkai 日本ジェンダー学会) ${ }^{68}$; l'université Ochanomizu fonde un Centre d'études de genre (Jendā kenkyū sentā ジェンダー研究センター) en $1996^{69}$, bientôt suivi en 1998 d'un Journal des études de genre (Jendā kenkyū ジェンダー研究) à parution annuelle. Peu à peu, les études de genre prennent donc leur place dans le paysage académique japonais.

Le glissement de point de vue des études féminines aux études de genre n'est pas qu'une préoccupation académique : on le retrouve dans la sphère sociale, politique et médiatique. Il n'est plus question de rendre visible uniquement la place ou l'histoire des femmes, il s'agit désormais de comprendre les rapports hommes-femmes, mais aussi d'interroger les normes masculines et féminines au sein des schémas familiaux. Dans les années 1990 les médias relaient largement une certaine inquiétude concernant les évolutions de la famille : on s'inquiète de la dénatalité (shōshika 少子化) qui se profile, mais également de la tendance au

66. Les recherches en histoire des femmes (joseishi 女性史) se poursuivent notamment ; le clivage entre études féminines et études de genre persiste dans le cas du Japon, du fait du développement des premières.

67. La publication d'un numéro spécial du journal Asahi en 2002 témoigne la visibilité qu'obtiennent les études de genre.

68. Le site est disponible sous http://www.s.fpu.ac.jp/tukamoto/gender.htm (consulté le 3 mai 2013).

69. Le site du centre est disponible sur http://www.igs.ocha.ac.jp/ (consulté le 4 mai 2013). 
126 Cahiers d'études japonaises n²2

mariage tardif (bankonka 晚婚化), voire de la « dématrimonialité 》 (bikonka 非 婚化). La crise et le chômage de la « décennie perdue » remettent en question le lien fondamental entre virilité et travail : les rôles masculins ne se restreignent plus à celui du mari salarié et pourvoyeur de salaire. Le genre amène à reconsidérer la question de l'égalité et de la parité homme-femme : la sphère politique s'empare aussi de ces questions. Ainsi des instances au sein du gouvernement sontelles remaniées : en 1992, le secrétaire général du Cabinet devient « ministre responsable des problèmes des femmes » (Josei mondai tantō daijin 女性問題 担当大臣). Puis le gouvernement japonais s'engage en 1994 en créant un Conseil pour l'égalité des sexes (Danjo kyōdō sankaku-shitsu 男女共同参画室), qui déménage en 2001 dans le bureau du Cabinet (Danjo kyōdō sankaku kaigi 男 女共同参画会議). De cette nouvelle instance découle la loi fondamentale pour l'égalité des sexes en 1999 (Danjo kyōdō sankaku shakai kihonhō 男女共同参 画社会基本法) et sa mise en œuvre avec le «Plan fondamental pour l'égalité des sexes en $2000 \gg$ (Danjo kyōdō sankaku shakai kihon keikaku 男女共同参 画社会基本計画). Néanmoins, l'emploi des termes de 《 genre » et 《égalité des sexes » est alors controversé au sein des instances politiques : alors que les nouvelles bureaucrates féministes, les « fémocrates (femokuratto フェモクラ ツト) revendiquent ce vocabulaire, les hommes politiques en place le remplacent par « participation conjointe des hommes et des femmes » (danjo kyōdō sankaku 男女共同参画). Seuls subsistent les termes originaux en anglais : le nom officiel du bureau ministériel est celui de Gender Equality Bureau Cabinet Office, celui de la Loi est Basic Act for Gender-Equal Society et celui du Plan Basic Plan for Gender Equality ${ }^{70}$. L'administration s'est ainsi progressivement intéressée aux biais de

70. Osawa Mari, "Government Approaches to Gender Equality in the mid-1990s", Social Science Japan Journal, $\mathrm{n}^{\circ}$ 1, vol. 3, 2000, pp. 4-5. 
genre portés par les politiques publiques, et notamment les politiques sociales ${ }^{71}$. La relecture genrée se traduit ainsi de façon concrète au sein de la société japonaise, et non pas uniquement dans les cercles féministes et universitaires. Ehara Yumiko pense même que « cette transformation des "recherches sur les femmes" vers les études sur le genre, indépendamment de leur entrée dans le monde de la recherche, peut être regardée comme un changement plus fondamental dans le cadre plus large d'une institutionnalisation du féminisme ${ }^{72} \gg$. De cette façon, le genre permet une normalisation de certaines des revendications féministes : c'est dire son importance pour des réalisations concrètes, au-delà de sa validité théorique.

\section{Des études de genre aux études gaies et lesbiennes}

Les études de genre ont initié au Japon de nouvelles recherches : les « études gaies et lesbiennes ». Le terme japonais rezubian ando gei sutadizu レズビアン/ ゲイ・スタディーズ73, dérivé de l'anglais lesbian and gay studies ${ }^{74}$, apparaît à la fin des années 1990 pour désigner un nouveau champ de recherche, celui des études portant sur l'ensemble des sexualités et notamment l'homosexualité.

71. Le terme « genre » apparaît pour la première fois au sein du vocabulaire politique en 1996 dans le rapport intitulé «De la création de nouvelles valeurs pour le XXI ${ }^{\mathrm{e}}$ siècle : vision de l'égalité et de la parité homme femme » (Danjo kyōdō sankaku bijion nijūisseiki no arata na kachi no sōzō 男女共同参画ビジョンー21世紀の新たな 価值の創造). On passe ainsi d'une stratégie qui se concentre sur la suppression des discriminations évidentes entre les hommes et les femmes à une stratégie qui articule la position dominante des hommes et des discriminations de genre plus subtiles et difficiles à mettre en évidence.

72. Ehara Yumiko, op. cit., 2002, p. 42.

73. On trouve plusieurs transcriptions $\mathrm{du} \ll$ et » en japonais dans la coordination « gaies et lesbiennes » : un point, une barre oblique, ando アンド (de l'anglais and) ou en japonais (to と) ou encore avec le logogramme « \&».

74. L'ordre des termes varie indifféremment entre études gaies et lesbiennes ou études lesbiennes et gaies, et de la même façon en japonais. 
128 Cahiers d'études japonaises n²2

Deux facteurs principaux peuvent expliquer cette chronologie propre au Japon ${ }^{75}$. Le premier tient à la nouvelle approche critique de la sexualité que proposent les études de genre ${ }^{76}$. On y démonte en effet le mythe d'une hétérosexualité naturelle, ce qui bouscule la sexologie et les études médicales de la sexualité, qui adoptent majoritairement une vision pathologique pour caractériser ce qui ne correspond pas aux pratiques hétérosexuelles ${ }^{77}$. À partir du moment où les rapports entre sexe, genre et sexualité sont dissociés et dénaturalisés, de nombreuses perspectives émergent, et des jeunes chercheurs s'y engagent ${ }^{78}$. De plus en plus de chercheurs, issus de différentes disciplines, se plongent dans une relecture des nombreuses publications communes et scientifiques sur l'homosexualité, telles que des études médicales, littéraires ou historiques ${ }^{79}$. Ils s'attachent à analyser des aspects jusqu'alors impensés de la sexualité. Cette relecture de la sexualité fait exploser les tabous ou les jugements moraux qui entravaient la recherche ${ }^{80}$. La vision pathologique de l'homosexualité, y compris chez les féministes, commence à se

75. Les études LGBT naissent dans plusieurs universités aux États-Unis dès les années 1970, avec en 1972 le premier programme d'études gaies et lesbiennes à l'université Sacramento en Californie, mais essaiment plus tardivement dans les autres pays d'Europe pour des raisons particulières à chaque pays. Au Japon, les études LGBT ont pu se développer après l'institutionnalisation des études de genre dans les années 1990, à la suite du renouvellement des recherches sur la sexualité, de la réception des études LGBT anglophones et de l'essor militant de certains groupes LGBT japonais.

76.La dynamique qu'apportent les études de genre ne doit pas occulter le fait qu'un courant de recherche sur la sexualité existe bien avant au Japon. La sexologie et la gynécologie deviennent des disciplines scientifiques entre la fin du XIX ${ }^{\mathrm{e}}$ siècle et le début du $\mathrm{XX}^{\mathrm{e}}$ siècle.

77. Comme la psychiatrie le faisait déjà, on s'interroge de nouveau sur la bicatégorisation normal/pathologique pour définir les pratiques et les identités sexuelles. On sait combien cette réflexion doit aux écrits de Georges Canguilhem et de Michel Foucault.

78. Cette nouvelle génération de chercheurs est formée avec les outils du genre.

79. Takemura Kazuko, "Feminist Studies/Activities in Japan: Present and Future", Lectora, $\mathrm{n}^{\circ} 16,2010$ p. 13-33, disponible sur dialnet.unirioja.es/descarga/articulo/3325949.pdf (consulté le 11 janvier 2013).

80. Ibid., pp. 15-16. 
fissurer ${ }^{81}$. On parle ainsi dans les années 1990 d'une renaissance de la sexologie et les études sur la sexualité, en référence à la remarquable hausse de telles publications dans les années $1920^{82}$. Parallèlement, les ouvrages non japonais sur la sexualité au Japon apparaissent. Une dynamique de recherche plus globale se met alors en place $^{83}$. Ainsi les études de genre, en déconstruisant le sexe, ont-elles ouvert une réflexion sur les pratiques, les représentations et les rapports entre hétéro/homo/ bi/trans-sexualités.

Le croisement entre activistes $\mathrm{LGBT}^{84}$ et universitaires féministes (ou LGBT) constitue le deuxième facteur qui marque la naissance des études gaies et lesbiennes ${ }^{85}$. Ce sont surtout des personnes non hétérosexuelles, universitaires ou non, des «personnes concernées » (tōjisha 当事者) qui ont d'abord relayé les

81. Ueno Chizuko est revenue, dans les années 2000, sur les propos à caractère homophobe qu'elle tenait dans ouvrage de 1986, intitulé Onna to iu kairaku 女という快楽 (De la jouissance d'être femme) aux éditions Keisō shobō.

82. NARITA Ryūichi, “The Overflourishing ofSexualityin 1920s Japan”, in Wa Kita Haruko, Ueno Chizuko, Anne Bouchy (eds), Gender and Japanese History. Volume 1. Religion and Customs/the Body and Sexuality, Ōsaka, Osaka University Press, 1999, pp. 345-370.

83. Sabine Früнstück, "Genders and Sexualities", in Jennifer Robertson (ed.), $A$ Companion to the Anthropology of Japan, Oxford, Blackwell, 2008, pp. 167-181.

84. On retrouve cet aspect militant dans les choix d'écriture : rezubian レズビアン, ce n'est pas resubianレスビアン! La différence participe à la question identitaire : emprunté au français, le terme resubian s'ancre dans un contexte littéraire et reste largement employé dans les dictionnaires. Le terme rezubian, emprunté à l'américain dans les années 1960, correspond au lesbianisme féministe : il reste plus revendicatif.

85. On doit aussi prendre en compte l'influence du féminisme lesbien radical qui amorce dès les années 1970 une réflexion sur l'homosexualité féminine et sa version politique, le lesbianisme. Minoritaires et marginalisées au sein des courants féministes, les lesbiennes japonaises n'ont pas pu initier au sein du monde universitaire la réflexion sur l'hétéronormativité, alors que cette dynamique s'est produite au États-Unis. Les mouvements lesbiens se désolidarisent rapidement des mouvements féministes des années 1970 et 1980, qui les reconsidèrent dans les années 1990, notamment à travers les polémiques entre femmes japonaises et femmes asiatiques lors des débats portant sur le système de femmes de réconfort mis en place durant la guerre. 


\section{CIPANGO}

130 Cahiers d'études japonaises n²2

interrogations sur l'hétéronormativité ${ }^{86}$. L'essai de Fushimi Noriaki, intitulé $M a$ vie privée gaie : nouvelles théories de l'amour ${ }^{87}$, fait un certain effet en 1991, et ouvre une brèche sur le monde encore clos de l'homosexualité ${ }^{88}$. Plusieurs personnalités commencent alors à affirmer publiquement leur homosexualité. Dans la continuité des études de genre, l'université, quant à elle, se met à traduire plusieurs auteurs américains sur le sujet, qui font alors figure de référence de l'autre côté de l'Atlantique ${ }^{89}$. La déconstruction de l'hétérosexualité et des autres sexualités commence alors. Des chercheurs engagés publient les premiers ouvrages qui systématisent la réflexion apportée par les études gaies et lesbiennes. On distingue au sein de cette nouvelle génération des chercheurs clairement engagés du fait de leur orientation sexuelle, dont notamment Kazama Takashi 風間孝 (1967-), Kawaguchi Kazuya 河口和也 (1963-), Tazaki Hideaki 田崎英明 (1960-), et d'autres spécialisés dans les études de genre comme Takemura Kazuko. On voit ainsi comment les études de genre, conjuguées avec une certaine part d'activisme LGBT porté par quelques universitaires, ont donné naissance aux études gaies et lesbiennes.

De 1990 à nos jours, les thématiques des études gaies et lesbiennes se développent. Les premiers récits de vie, dans lesquels la révélation publique de l'homosexualité s'avère centrale, ont nourri la réflexion universitaire ${ }^{90}$. On

86. Mark McLelland, “The Role of the 'Tojisha' in Current Debates about Sexual Minority Rights in Japan”, Japanese Studies, n² 29, vol. 2, 2009, pp. 193-207.

87. Fushimi Noriaki 伏見憲明, Puraibèto gei raifu-posuto ren.aironプライベート・ ゲイ・ライフーポスト恋愛論, Tōkyō, Gakuyō shobō 学陽書房, 1991.

88. Suganuma Katsuhiko, "Enduring Voices: Fushimi Noriaki and Kakefuda Hiroko's Continuing Relevance to Japanese Lesbian and Gay Studies and Activism”, Intersections: Gender, History and Culture in the Asian Context, $\mathrm{n}^{\circ}$ 14, Nov. 2006, disponible sous http://intersections.anu.edu.au/issue14/suganuma.htm (consulté le 15 décembre 2014).

89. En particulier Leo Bersani, David M. Halperin, Judith Butler, Evelyn KosofskySedgwick, Theresa De Lauretis.

90. Autrement dit, le coming out, contraction de l'expression «sortir du placard » en anglais (coming out of the closet), qui désigne l'annonce volontaire d'une orientation sexuelle ou d'une identité de genre. 
interroge l'actualité de l'homosexualité dans différentes disciplines ${ }^{91}$. Parmi ces contributions, on dénombre :

. le numéro spécial du journal progressiste Takarajima (L'île aux trésors) intitulé Histoires de ces femmes qui aiment les femmes, publié en 1987, devenu rapidement une référence ${ }^{92}$ - étant donné le peu d'information sur l'homosexualité féminine à l'époque, il est alors souvent cité dans les cercles lesbiens ${ }^{93}$;

. les premiers écrits de nature autobiographique ou biographique, qui forment un matériau encore utilisé pour comprendre la place de l'homosexualité dans le Japon contemporain. Au livre de Fushimi Noriaki succède, en 1992, Etre lesbienne de Kakefuda Hiroko, qui intervient à la radio ou à la télévision pour le commenter ${ }^{94}$. D’autres ouvrages suivent : en 1993 celui de Izumo Marō, L'amour au-dessus d'une planche à découper ${ }^{95}$; en 1995 Coming out! de Sasano Michiru ${ }^{96}$; en 1998 Vivre en tant qu'homosexuel d'Itō Satoru' ${ }^{97}$; en 1999 le Manifeste d'une professeure lesbienne. Un

91. Les ouvrages universitaires retraçant l'histoire de l'homosexualité existent déjà, mais ne concernent pas le Japon de l'après-guerre.

92. Hirosawa Yumi 広沢有美 (dir.), Onna o ai suru onna no monogatari 女を愛する 女の物語 (Histoires de ces femmes qui aiment les femmes), Bessatsu Takarajima 別冊宝 島 (Numéro spécial Takarajima), mai 1987.

93. Ce numéro spécial est dirigé par Sawabe Hitomi sous le nom de plume de Hirosawa Yumi.

94. KAKEFUDA Hiroko 掛札悠子, Rezubian de aru to iu koto レズビアンであるとい うこ (Être lesbienne), Tōkyō, Kawade shobō shinsha 河出書房新社, 1992.

95. Izumo Marō 出雲まろう, Manaita no ue no koi まな板のうえの恋 (L'amour au-dessus d'une planche à découper), Tōkyō, JICC shuppankyoku JICC出版局, 1993.

96. SASAno Michiru 笹野みちる, Coming out! (Sortir du placard !), Tōkyō, Gentōsha 幻冬舎, 1995.

97. ITō Satoru 伊藤悟, Dōseiaisha toshite ikiru 同性愛者として生きる (Vivre en tant qu'homosexuel), Tōkyō, Akashi shobō 明石書房, 1998. 


\section{CIPANGO}

132 Cahiers d'études japonaises n²2

coming out pour tisser des liens, d' Ikeda Kumiko ${ }^{98}$; ainsi que la publication en anglais de Coming out in Japan en $2001^{99}$. On remarque également la biographie romancée de l'écrivaine Miyamoto Yuriko et de son amante, la traductrice Yuasa Yoshiko ${ }^{100}$.

Les études gaies et lesbiennes se constituent comme champ de recherche avec les premières publications scientifiques. On trouve notamment :

. le numéro 8 (volume 2) de janvier 1996 de la revue Hibyō kükan (Espace critique) avec un dossier spécial intitulé «Sexe/genre» (セックス/ ジェンダー) qui comprend, entre autres, des traductions d'articles de Judith Butler, Evelyn Kosofsky-Sedgwick, Leo Bersani, David Halperin ${ }^{101}$;

. un numéro de novembre 1996 du magazine Yuriika (Eureka) qui introduit les études queer ${ }^{102}$;

98. IkedA Kumiko 池田久美子, Sensei no rezubian sengen - Tsunagaru tame no kamuauto 先生のレズビアン宣言 つながるためのカムアウト (Manifeste d'une prof lesbienne, un coming out pour tisser des liens), Kyōto, Kamogawa shuppan かもが わ出版, 1999.

99. Ito Satoru, Yanase Ryuta (eds), Coming Out in Japan, Melbourne, TransPacific Press, 2001.

100. SaWABE Hitomi 沢部仁美, Yuriko, dasuvidāniya 百合子 ダスヴェイダーニヤ (Dasvidania Yuriko), Tōkyō, Bungei shunjū 文藝春秋, 1990.

101. Numéro spécial de la revue Hihyō kükan 批評空間 (Espace critique), Tokushū, shükyō to shükyō hihan. Sekkusu/jendā 特集=宗教と宗教批判セックス/ジェンダ - (La religion et la critique de la religion - Le sexe et le genre), n ${ }^{\circ}$ 8, vol. 2, Tōkyō, Ōta shuppan 太田出版, janvier 1996. Le sommaire est disponible sur les archives du site http://www36.atwiki.jp/aabiblio/pages/64.html\#id_f5c68938 (consulté le 5 décembre 2014).

102. Yuriika ユリイカ (Eureka), Kuia rìdingu クィア・リーディング (La relecture queer), Tōkyō, Seidosha 青土社, novembre 1996, vol. 28, nº 13. 
. un numéro spécial en mai 1997 de la revue Gendai shisō intitulé Études gaies et lesbiennes (レズビアン・ゲイスタディーズ) ${ }^{103}$;

. un numéro spécial du journal Asahi intitulé « Comprendre le genre » (2002), qui fait office d'ouvrage de vulgarisation ${ }^{104}$;

. un numéro spécial en octobre 2015 de la revue Gendai shisō intitulé 《LGBT : la réalité au Japon et dans le monde »(LGBT日本と世界の リアル) ${ }^{105}$.

Parallèlement à la publication de ces numéros spéciaux paraissent, à la fin des années 1990 et dans les années 2000, des ouvrages académiques complets qui se proposent de délimiter ce nouveau champ de recherche et de construire l'objet « homosexuel » comme connaissance ${ }^{106}$. On retiendra notamment : Gay studies (1997) ${ }^{107}$, Genre/Sexualité (2000) ${ }^{108}$, Politique de la sphère intime

103. Gendai shisō 現代思想 (Revue de la pensée d'aujourd'hui), Sōtokushū Lezubian/gei sutadizu 総特集 レズビアン/ゲイ・スタディーズ (Numéro spécial. Les lesbian/ gay studies), Tōkyō, Seidosha 青土社, mai 1997.

104. Collectif, Jendā ga wakaru ジェンダーがわかる (Comprendre le genre), Asabi Shinbun Extra Report and Analysis Special Number, AERA Mook, n' 78, 2002, 176 p.

105. Gendai shiso 現代思想 (Revue de la pensée d'aujourd'hui), Tokushū LGBT nihon to sekai no riaru 特集 LGBT日本と世界のリアル (Numéro spécial LGBT : la réalité au Japon et dans le monde), Tōkyō, Seidosha 青土社, octobre 2015.

106. On trouve également le numéro spécial 17 de la revue Kaihō shakaigakukenkyū 解放 社会学研究 (Recherches en sociologie pour la libération humaine), Tokushū Rezubian/ gei sutadizu pēpābakku 特集 レズビアン/ゲイ・スタディーズ ペーパーバック (Le livre de poche des études gay et lesbiennes), 2003.

107. Keith VIncent ヴィンセント・キース, KAzAma Takashi 風間孝 et KAWAGUCHI Kazuya 河口和也, Gei sutadizu ゲイ・スタディーズ (Les études gaies), Tōkyō, Seidosha 青土社, 1997.

108. TAZAKI Hideaki 田崎英明, Jendā/sekushuariti ジェンダー／セクシュアリテ イ (Genre et sexualité), Tōkyō, Iwanami shoten 岩波書店, 2000. 
134 Cahiers d'études japonaises n²2

$(2003)^{109}$. Ainsi les sciences sociales japonaises définissent-elles les études gaies et lesbiennes comme un domaine à part, au sein des sujets abordés par les études de genre. La recherche japonaise continue de s'enrichir de la recherche anglophone, qui demeure la plus prolifique pour ce qui est des gay studies, et cette dynamique s'accentue lorsque des travaux japonais sont traduits en anglais, mais aussi lorsque des chercheurs japonophones ${ }^{110}$ inscrits dans la dynamique des Lesbian and gay studies anglo-saxonnes publient sur le Japon ${ }^{111}$. Certains enseignements, à l'initiative des chercheurs spécialistes, se mettent en place dans les années 2000, limités à des modules et séminaires au sein des cursus universitaires, pour la plupart en sociologie ou histoire, souvent au sein des programmes d'études de genre ${ }^{112}$.

De façon remarquable, les études gaies et lesbiennes se développent en parallèle des mouvements militants féministes et LGBT. Ces deux mondes sont loin d'être perméables. En effet, quelques universitaires (souvent des personnes non hétérosexuelles) mènent par ailleurs une vie associative et militante ${ }^{113}$. À l'inverse, les militants féministes et LGBT lisent la production académique et s'en inspirent. Les démarches scientifique et militante s'éclairent donc l'une l'autre. Cette imbrication s'avère d'autant plus forte dans les années 1990, lorsque plusieurs associations LGBT de taille conséquente se développent. Ces associations sont plus visibles que les premiers cercles lesbiens ou gais, pour la plupart apparus dans les années 1970. De ce fait, la réalité de la vie des personnes LGBT se dévoile un peu par touches dans les médias japonais. Par exemple, des

109. SAITŌ Jun.ichi 斉藤純一, Shinmitsuken no poritikkusu 親密圈のポリティック ス (La politique de l'intime), Kyōto, Nakanishiya shuppan ナカニシヤ出版, 2003.

110. On dénombre les travaux de Mark McLelland, Romit Dasgupta, Charon Shalmers, Sabine Frühstück, J. Keith Vincent et James Welker.

111. Des chercheurs comme Ogino Miho ou Takemura Kazuko, qui ont traduit et commenté des ouvrages essentiels de Butler ou Scott, n’hésitent pas à travailler sur les textes anglais.

112. Le journal Asahi recense en 2002 au moins 120 universités dans lesquelles sont dispensés des enseignements en études de genre.

113. Suganuma Katsuhiko, op. cit. 2006. 
hommes gais apparaissent dans les séries et émissions de la télévision japonaise. La réalité homosexuelle devient un peu plus visible dans les médias ${ }^{114}$. On parle même d'un gay boom (gei būmu ゲイブーム ${ }^{115}$ ). Cette visibilité reste néanmoins très limitée. En outre, les médias japonais s'alarment dans la première moitié des années 1990 de l'épidémie du virus du VIH, qu'ils associent clairement à l'homosexualité masculine ${ }^{116}$. On parle de panique du SIDA (eizu panikku エイ ズ・パニック ${ }^{117}$ ). Les propos tenus pendant cette période stigmatisent de façon durable les hommes gais et amalgament homosexualité et contamination. En réaction à cette désinformation, à une époque où les phénomènes de transmission du SIDA ou autres MST sont méconnus et souvent tus, plusieurs associations gaies se spécialisent dans l'information et la prévention du SIDA. Des centres d'accueils et d'information pour les maladies sexuellement transmissibles, ainsi que des centres de dépistage, se déploient sur le territoire, notamment grâce à des associations LGBT comme JILGA, OCCUR ou Ōsaka Gay Community ${ }^{118}$. Lors de la décennie suivante, le ministère du Travail, de la Santé et du Bien-être social alloue des fonds pour des groupes LGBT de prévention du sida, plus nombreux ${ }^{119}$. Les années 1990 correspondent donc à la fois à la définition des études gaies et

114. Dans les années 1990, des personnages gais, travestis, intersexes, et plus rarement lesbiens, apparaissent dans les émissions télévisées, ainsi que dans quelques films. Leurs histoires d'amour (et donc l'homosexualité) sont évoquées de façon plus ou moins réalistes.

115. Mark McLelland, Male Homosexuality in Modern Japan: Cultural Myths and Social Realities, London, Routledge Curzon, 2000, pp. 130-133.

116. Gregory M. Pflugfelder, Cartographies of Desire: Male-Male Sexuality in Japanese Discourse, 1600-1950, Berkeley, Los Angeles and London, University of California Press, 1999 , p. 20.

117. KaZAma Takashi 風間孝, KaWAguChi Kazuya 河口和也, Dōseiai to iseiai 同性 愛と異性愛 (Homosexualité et hétérosexualité), Tōkyō, Iwanami shinsho 岩波新書, 2010, p. 6-36.

118. Érick Laurent, Les Chrysanthèmes roses. Homosexualités masculines dans le Japon contemporain, Paris, Les Belles Lettres, collection «Japon », 2011, p. 155-156 et p. 161-162.

119. Ibid., p. 160. 
136 Cahiers d'études japonaises n²2

lesbiennes en tant que champ de recherche, au développement des militantismes et associations LGBT, ainsi qu'à une visibilité très limitée des réalités LGBT au sein du grand public.

Recherche, militantisme et visibilité LGBT se déploient dans les années 2000, sans forcément mettre en avant l'homosexualité masculine ${ }^{120}$. Les termes de «LGBT» ou «LGBTQ», moins restrictif que « gai et lesbien », s'imposent alors. À l'université, on parle d'études LGBT (eru jī bī tī sutadīzu LGBTスタデ イーズ), expression empruntée à l'anglais LGBT studies. Pour les chercheurs, il ne s'agit plus seulement de s'interroger sur l'homosexualité, mais sur les normes et pratiques des sexualités, y compris celles qui définissent l'hétérosexualité. Au sein des mouvements militants (féministes et LGBT), on adopte alors le terme de « minorité sexuelle (sekushuaru mainoriti セクシュアルマイノリティ). De cette façon, on tient ensuite compte de l'ensemble des minorités sexuelles, qui s'opposent au discours de l'hétérosexualité normative. Les militants LGBT au Japon veulent que soient reconnues les discriminations qu'ils subissent. Pour ce faire, des associations, militants et personnalités politiques s'emparent des outils juridiques ${ }^{121}$. Ces batailles politiques et juridiques aboutissent à plusieurs changements : organisation régulière des marches des fiertés, condamnation de certains actes et propos homophobes ${ }^{122}$, autorisation du changement de sexe en $2003^{123}$, reconnaissance en 2009 du mariage gai pour les Japonais homosexuels

120. Le fait de s'interroger d'abord sur l'homosexualité masculine n'en demeure pas moins de l'androcentrisme.

121. Érick Laurent, "Sexuality and Human Rights: An Asian Perspective", in Helmut Graupner, Phillip Tahmindjis (eds), Sexuality and Human Rights, New York, Haworth Press, 2005, pp. 163-225.

122. Par exemple, l'association OCCUR s'est engagée très tôt dans une refonte des termes à caractère homophobe. Elle mène un procès de 1991 à 1997 qu'elle gagne contre l'auberge de jeunesse de Fuchū à Tōkyō qui avait refusé de loger des homosexuels.

123. Le texte de la loi est disponible sur http://law.e-gov.go.jp/htmldata/H15/ H15HO111.html (consulté le $1^{\text {er }}$ décembre 2014). 
avec des ressortissants de pays où le mariage homosexuel est reconnu ${ }^{124}$. Ainsi les milieux militants et universitaires se penchent-ils sur la question de la discrimination des personnes LGBT. Paraissent alors des livres comme Les minorités sexuelles racontent elles-mêmes l'homosexualité, la transsexualité et l'intersexualité. Pour une sexualité humaine variée (2003) ${ }^{125}$, Pour ceux qui veulent en savoir plus sur les minorités sexuelles. Pour une société plus tolérante (2008) ${ }^{126}$, La pauvreté Arc-en-ciel. Guide de survie LGBT ! Repeindre la faim et la soif aux couleurs de l'arc-en-ciel (2010) ${ }^{127}$. Les années 2010, quant à elles, suivant les changements de société, esquissent la question des familles homoparentales, avec la revendication d'un système japonais de partenariat ou de mariage : Le partenariat homosexuel. Connaître la législation du mariage gai et du partenariat (2004) ${ }^{128}$,

124. Le ministère de la Justice émet le 26 mars 2009 un avis sur la reconnaissance des mariages homosexuels étrangers. Fukushima Mizuho (alors à la tête du parti socialiste) a beaucoup œuvré pour.

125. IKedA Kumiko 池田久美子, OKaBE Yoshihiro おかべよしひろ, KIMURA Kazunori 木村一紀, KuROIwa Ryūtarō 黒岩竜太郎, TAKATORI Shōji 高取昌 二, Dohi Itsuki 土肥いつき, Mryazaki Rumiko 宮崎留美子, Alexander Ronni, Sekushuaru mainoriti, dōseiai, seidōitsusei shōgai, intāsekkusu no tōjisha ga kataru ningen no tayōna sei セクシュアルマイノリテイ、同性愛、性同一性障害、インター セックスの当事者が語る人間の多様な性 (Les minorités sexuelles racontent ellesmêmes l'homosexualité, la transsexualité et l'intersexualité, Pour une sexualité humaine variée), Tōkyō, Akashi shoten 明石書店, 2006 (première édition en 2003).

126. SugiYama Takashi 杉山貴士, Kikitai shiritai seiteki mainoriti, tsunagari aeru shakai no tameni 聞きたい知りたい性的マイノリティ つながりあえる社会 のために (Pour ceux qui veulent en savoir plus sur les minorités sexuelles. Pour une société plus tolérante), Ōsaka, Nihon kikanshi shuppan sentā 日本機関紙出版センタ $-, 2008$.

127. Susumu Ryū 超竜, Niji-iro no hinkon, LGBT sabaibaru! Reinbōkarā dewa nuritsubusenai, «ue to 《kawaki»虹色の貧困 LGBTサバイバル！レインボーカ ラーでは塗りつぶせない「飢え」と「渇き」 (La pauvreté Arc-en-ciel. Guide de survie LGBT ! Repeindre la faim et la soif aux couleurs de l'arc-en-ciel), Tōkyō, Sairyūsha 彩流社, 2010.

128. Akasugi Yasunobu 赤杉康伸, Tsuchiya Yuki 土屋ゆき, Tsutsui Makiko 筒井 真樹子, Dōsei pātonā, Dōseikon, domesutikku pātonāshippu-hōo shiru tameni, 同性パー トナー、同性婚・DP法を知るために, Tōkyō, Shakai hihyōsha 社会批評社, 2004. 


\section{CIPANGO}

138 Cahiers d'études japonaises n²2

ou Le partenariat, mode de vie et système ; mariage, concubinage et mariage gai (2007) ${ }^{129}$ et Le livre de référence sur la vie en partenariat homosexuel. De la cohabitation, des impôts et de l'assurance sociale jusqu'à la dépendance, le décès et la succession (2009) ${ }^{130}$. Ce type de publication indique que la situation des personnes LGBT devient peu à peu une question politique et juridique. L'adoption et la diffusion du terme LGBT dans les médias dénotent la visibilité progressive de ces questions au sein de la société japonaise. Le développement des études gaies et lesbiennes s'inspire et se nourrit du militantisme de terrain. Les deux s'ancrent largement dans l'actualité politique, où émergent progressivement des voix en faveur des droits des minorités sexuelles. Universitaires et activistes se rejoignent parfois dans leur démarche, lorsqu'ils s'interrogent sur la réalité qu'ils cherchent à comprendre ou à transformer, même si leurs publications et leurs réseaux diffèrent. On retiendra de ce panorama des études gaies et lesbiennes japonaises (ou études LGBT), encore marginales dans le système universitaire, qu'elles sont indissociables d'une histoire sociale et d'un certain type de militantisme LGBT. Ces études, même nourries par la réflexion anglo-saxonne sur les questions LGBT, se développent de façon autonome et s'ancrent résolument dans l'histoire et la société du Japon. Elles dévoilent une vaste étendue de thèmes qui restent à défricher à travers les études de genre et les études LGBT.

129. Sugiura Ikuko 杉浦郁子, Nomiya Aki 野宮亜紀et ŌE Chizuka 大江千束, Pätonāshippu : seikatsu to seido, kekkon, jijitsukon, dōseikon, パートナーシップ・生活 と制度一結婚、事実婚、同性婚 (Le partenariat, mode de vie et système ; mariage, concubinage et mariage gai), Tōkyō, Ryokufū shuppan 緑風出版, 2007.

130. Nagayasu Shibun 永易至文, Dōsei pātonā seikatsu tokuhon, dōkyo zeikin hoken kara kaigo shibetsu sōzoku made 同性パートナ一生活読本 同居・税金・保険から 介護・死別・相続まで (Le livre de référence sur la vie en partenariat homosexuel : de la cohabitation, des impôts et de l'assurance sociale jusqu'à la dépendance, le décès et la succession), Tōkyō, Ryokufū shuppan, 2009. 


\section{Les études queer au Japon : vers une troisième vague féministe}

Cet article ne serait pas complet s'il n'examinait pas la genèse de ce qu'on nomme désormais les «études queer » (kuia sutadizu クイアスタディーズ) ${ }^{131}$. On exposera d'abord le cas américain pour comprendre les concepts de la critique queer. Issu du féminisme et des études gaies et lesbiennes américaines, la critique queer, fortement implantée à l'université, dénonce le conservatisme des groupes féministes ainsi que gai et lesbien, qui fondent leur revendication collective sur une nature commune, et qui aspirent à une vie calquée sur le modèle dominant (blanc, hétérosexuel, bourgeois). Le paradigme identitaire éclate : il n'est plus question de former des groupes particuliers (femmes, étrangers, homosexuels...), mais de se positionner par rapport et contre la norme dominante ${ }^{132}$. Ainsi la position queer est-elle anti-essentialiste, elle refuse de penser l'homosexualité comme un choix d'objet : l'identité (sexuelle notamment) est considérée comme non stable. La critique queer comporte une charge politique importante puisqu'elle considère l'ensemble des minorités, perçues dans une logique de résistance qui interroge le sens et la réappropriation des normes dominants/dominés. On s'éloigne ainsi du schéma calqué sur la pensée socialiste, avec une séquence oppression $=>$ lutte => obtention de l'égalité, suivi par les mouvements féministes ainsi que gais et lesbiens. La critique queer s'avère la fille contestatrice des minorités (sexuelles, ethniques, religieuses) qui se pensent à travers les études post-coloniales (les subaltern studies, les études de genre...) : née après la chute de l'URSS, elle affronte le vide provoqué par l'abandon de l'idéologie marxiste et l'expansion de plus en plus importante du néolibéralisme, mais ne rejoint pas les réactions identitaires

131. Le terme «queer ( « étrange » en anglais) est récupéré à la toute fin des années 1980 par les activistes gais aux États-Unis, qui retournent avec ironie le stigmate et l'insulte, le mot en vient à désigner l'ensemble des minorités sexuelles (gais, lesbiennes, bisexuelles, intersexuels, transgenres, transsexuels), et également ceux qui ne veulent pas être réduits à des catégories ainsi fermées.

132. Laure Bereni, Sébastien Chauvin, Alexandre Jaunait, Anne Revillard, op. cit., 2012, p. 49-53. 
140 Cahiers d'études japonaises n²2

(les féministes, les gais, les noirs...) qui se structurent alors ${ }^{133}$. La mouvance queer, quant à elle, réaffirme au contraire la nécessité d'une lecture non identitaire qui ne prenne pas pour acquis les catégories féminin/masculin/hétérosexualité/ homosexualité ${ }^{134}$. Le terme de queer, employé pour la première fois dans le champ universitaire en 1990 lors d'un colloque intitulé « Queer Theory », organisé par la professeure Teresa de Lauretis ${ }^{135}$ à l'université de Californie-Santa Cruz, se répand très rapidement dans le monde académique nord-américain, alors même qu'il se veut contre les étiquettes. Paru la même année en anglais, Gender Trouble, de Judith Butler, devient l'ouvrage fondateur de la théorie queer. La philosophe déroule une pensée fortement inspirée de Foucault, Derrida ou Hocquenghem, qui s'attache à déconstruire les catégories : le sexe y est dénaturalisé, ainsi que le genre, qui restent des manières de signifier les rapports de pouvoir, et la présomption d'hétérosexualité y est critiquée. Butler explique ainsi qu'elle souhaite reformuler le poststructuralisme dans une perspective proprement féministe ${ }^{136}$ : contrairement aux mouvements identitaires féministes ainsi que gais et lesbiens, le genre n'est pas fixé, il est trouble, mouvant, on peut se le réapproprier à travers un jeu performatif. Ce livre, dont la complexité du projet de déconstruction du genre donne encore matière à réfléchir, est rapidement traduit et il s'exporte alors dans les autres pays.

La réception de la critique queer américaine au Japon s'effectue très tôt, alors même que les études de genre et LGBT se développent. Judith Butler est rapidement présentée au Japon : le premier chapitre de Gender Trouble, traduit

133. La critique queer a finalement un impact moins important aux États-Unis qu'en Europe où elle s'affirme à travers des mouvements radicaux de gauche non affiliés aux partis traditionnels.

134. On peut ainsi voir l'ajout du terme « queer » à l'acronyme LGBTQ, afin de désigner l'ensemble des sexualités non normatives, mais aussi de toute personne qui ne se reconnaitrait pas dans les catégories utilisées.

135. Théoricienne féministe, lesbienne, et professeure d'histoire de la conscience, Teresa de Lauretis a notamment écrit en 1987 Technologies of Gender: Essays on Theory, Film, and Fiction (partiellement traduit en français notamment dans l'ouvrage Teresa de Lauretis. Théorie queer et culture populaire, paru aux éditions La Dispute en 2007).

136. Judith Butler, Trouble dans le genre, Paris, La Découverte, 2005, p. 27-28. 
par Ogino Miho, est publié en 1994 dans la revue Shisō 思想 (La pensée). À cela s'ajoute la traduction par Takemura Kazuko d'un entretien de Judith Butler mené en 1993 par Peter Osborne et Lynne Segal, traduction publiée dans la revue Hihyō kükan 批評空間 (Espace critique) en 1996. L'ouvrage de Butler est traduit intégralement en 1999 par Takemura Kazuko sous le titre de Jendā toraburu ジェ ンダー・トラブル ${ }^{137}$. Les traductions d'articles et ouvrages clés, comme ceux de Lauretis, Sedgwick ou Halperin, se succèdent et permettent d'étayer la réflexion japonaise. La bonne connaissance des auteurs français, qui ont inspiré la nébuleuse queer d'un champ intellectuel étatsunien parlant volontiers de french theory, permet aux sociologues japonais de s'approprier plus rapidement les concepts et auteurs queer ${ }^{138}$ (qui s'appuient notamment sur l'œuvre de Michel Foucault ${ }^{139}$ ). Les initiatives de traductions personnelles d'universitaires féministes et militants (notamment Takemura Kazuko, et des membres académiques de l'association OCCUR) permettent de constituer et diffuser un premier corpus de textes. Un numéro spécial de Hihyō kükan est ainsi publié au début de l'année 1996 sur le thème « sexe/genre » pour introduire les travaux de divers théoriciens queer américains, dont la reconnaissance dépasse les frontières de leur propre

137. ジュディース・バトラー Judith BUTLER, Jendā toraburu feminizumu to aidentiti no kakuran ジェンダートラブル フェミニズムとアイデンティティの 攪乱 (Trouble dans le genre, le féminisme et la subversion de l'identité), Tōkyō, Seidosha 青土社, 1999, $300 \mathrm{p}$.

138. KAWAHARA Yukari 川原ゆかり, Wakamono bunka to sekushuariti, karuchuraru sutadizu o megutte 若者文化とセクシュアリティカルチュラルスタディーズを めぐって (Culture jeune et sexualité : perspective des études culturelles), dans Jendā kenkȳu ジェンダー研究 (Le journal des études de genre), vol. 2, Ochanomizu joshi daigaku jendā kenkyū sentā nenpōお茶の水女子大学ジェンダー研究センター年報 (Rapport annuel du Centre d'études de genre de l'université Ochanomizu), mars 1999, p. 113.

139. Foucault demeure un auteur incontournable pour les études de genre, avec les trois tomes de son Histoire de la sexualité, non seulement pour sa façon de déconstruire la notion de sexe/sexualité, mais aussi pour sa réflexivité sur le contexte (la notion d' «épistémè ») de formation des connaissances, réflexion dans laquelle les études de genre, LGBT ou queer se sont également engagées. 


\section{CIPANGO}

142 Cahiers d'études japonaises n²2

pays ${ }^{140}$, tandis que la revue Gendai shisō publie en mai 1997 un numéro spécial intitulé «Études gaies et lesbiennes ». De la même façon, le magazine Yuriika (Eureka) propose une introduction au concept de queer et aux études gaies et lesbiennes ${ }^{141}$. Des essais de vulgarisation sont ensuite proposés, comme en 2002, avec la publication du numéro spécial du journal Asahi intitulé «Comprendre le genre », où plusieurs articles font référence aux études queer ${ }^{142}$. Les travaux de Judith Butler notamment sont largement commentés, et inspirent des essais relatifs à des auteurs japonais ${ }^{143}$. Une poignée d'universitaires engagés ${ }^{144}$, souvent eux-mêmes féministes et militants LGBT, en traduisant les premiers textes queer américains, et grâce à une connaissance antérieure des auteurs de la French theory, favorisent la découverte d'un corpus queer qui va leur permettre de s'insérer dans cette mouvance.

Les études queer ne trouvent cependant leur assise qu'à l'aube des années 2000. Le terme «queer , transcrit en katakana tel quel, devient kuiaクイア en japonais. La perspective queer apparaît efficace dans plusieurs disciplines, et l'ouvrage Kuia sutadizu (クイア・スタディーズ Études queer) de Kawaguchi Kazuya devient en 2003 le premier ouvrage universitaire de référence ${ }^{145}$. Il marque le début de l'institutionnalisation des théories queer au Japon, qui se matérialise en 2007 avec la création de la Société savante des études queer (Kuia gakkai ク イアー学会). Créée à l'initiative des universitaires réunis en assemblée générale

140. Takemura Kazuko, op. cit., 2010, p. 5-6.

141. Ibid., p. 5.

142. Collectif, Jendā ga wakaru ジェンダーがわかる (Comprendre le genre), Asahi Shinbun Extra Report and Analysis Special Number, AERA Mook, n 78, 2002.

143. On y trouve par exemple une relecture queer du poète Masaoka Shiki 正岡子 規 (1867-1902), dans un article de Keith J. Vincent.

144. Keith J. Vincent, "Queering Friendship: Takemura Kazuko", communication présentée le 20 avril 2013 à l'université Emory, dans le cadre d'un colloque intitulé « Sex, Gender, and Society: Rethinking Japanese Feminism »), texte intégral disponible sous http://worldwide-wan.blogspot.fr/2013/05/queering-friendship-takemura-kazuko-by. html (consulté le 22 août 2013).

145. KaWAguchi Kazuya 河口和也, Kuia sutadizu クイア・スタディーズ (Queer studies), Tōkyō, Iwanami shoten, 2003. 
à l'université de Tōkyō, sur le campus de Komaba, le 27 octobre $2007^{146}$, son premier colloque annuel national se tient à Hiroshima en novembre 2008. Depuis lors, la Société publie annuellement le Bulletin Ronsō kuia (論叢ク イア, Bulletin des recherches queer ${ }^{147}$ ). La diffusion de la critique queer se fait également par l'enseignement : des séminaires et modules apparaissent à la fin des années 2000, mais ces cours demeurent extrêmement marginaux, soutenus avant tout par les premiers passeurs de la mouvance queer ${ }^{148}$. Même au sein des études de genre, cette dernière reste aujourd'hui mal connue, méconnaissance encore plus marquée pour des universitaires venant d'autres départements ${ }^{149}$. Au sein d'un cercle restreint, la critique queer japonaise se construit et explore plusieurs thèmes dans des disciplines variées. Elle permet notamment d'approfondir les recherches portant sur la masculinité ${ }^{150}$ qui se sont développées dans les années $1990^{151}$. Ce faisant, elle redécouvre et questionne le principal biais de la production des connaissances : l'androcentrisme. En effet, l'objet « homme » avait été laissé de côté : la perspective du genre et du queer consiste à interroger cette masculinité

146. Compte-rendu numéro 9 du centre d'études de genre de l'université internationale chrétienne (ICU) disponible sur http://subsite.icu.ac.jp/cgs/pdf/NL009.pdf (consulté le 15 avril 2013).

147. Site du Ronsō kuia disponible sous http://queerjp.org/journal.html (consulté le 23 août 2013).

148. Les cours d'Ogino Miho à l'université Dōshisha, ceux de Kawaguchi Kazuya à l'université Shūdō à Hiroshima, ainsi que des cours à l'université ICU (qui a un département d'études LGBT) ou Ochanomizu.

149. Entretien avec Ogino Miho le 18 février 2013 à Kyōto, université Dōshisha.

150. Des groupes de recherche sur la masculinité se créent, portés par la réflexion qu'apporte le genre : le mouvement lib' pour les recherches sur les hommes, le centre des hommes en 1995, et le Tokyo Lib pour hommes en 1996. Une Histoire de la masculinité (danseishi 男性史) est publiée en plusieurs volumes.

151. Ces recherches font écho aux changements sociaux relatifs à la paternité et au statut des hommes; elles se situent dans le prolongement de mouvements masculins féministes activistes comme Les pères pour l'éducation de leurs enfants (Otoko no kosodate o kangaeru kai 男の子育てを考える会) en 1978, ou Les hommes mobilisés contre la prostitution en Asie (Ajia no baibaishun ni hantai suru otoko-tachi no kai アジアの売 買春に反対する男たちの会) en 1988. 
hégémonique qui faisait passer l'homme (mâle) pour le sujet universel et définissait le monde selon son point de vue, surtout quand il s'agissait de parler de la féminité et de la figure «femme ${ }^{152}$. La critique queer rejoint également les progrès établis en biologie et recherche médicale sur la définition du sexe : on s'interroge sur la part physiologique (chromosomique/gamétique/hormonale, parmi d'autres critères) du sexe en embryologie lors de la différentiation sexuelle ${ }^{153}$. Dans le prolongement de cette dénaturalisation du sexe/corps, les recherches sur le transsexualisme, l'intersexuation ${ }^{154}$, et les troubles de l'identité sexuelle, ainsi que la réassignation de sexe en chirurgie, progressent et contribuent à la complexité de ces études. Le prisme queer permet notamment de revisiter l'histoire ${ }^{155}$, l'histoire de l'art ${ }^{156}$, la littérature ${ }^{157}$, la sociologie. Son apport est important : en synergie avec les études de genre portant sur la sexualité, les identités sexuelles et les études LGBT, mais également d'autres domaines de recherche, divers champs ne cessent désormais d'être explorés.

152. Michèle Le Doeuff, Le Sexe du savoir, Paris, Flammarion, collection « champs », 2000, p. 130-133.

153. Collectif, Jendā ga wakaru ジェンダーがわかる (Comprendre le genre), op. cit., 2002, p. 132-141.

154. L'intersexuation correspond à une variation génétique comme pour les personnes porteuses des chromosomes sexuels XXY, XYY, XO, et concernerait (selon les critères retenus pour définir le sexe) une naissance sur 2000 (Laure Bereni, Sébastien CHAuvin, Alexandre Jaunait, Anne Revillard, op. cit., 2012, p. 34-39).

155. On redécouvre les variations des pratiques homosexuelles et de l'ensemble des sexualités non normatives à travers l'étude de la famille, de la prostitution, de l'organisation de la noblesse guerrière, de la vie monastique, par exemple, notamment à l'époque d'Edo.

156. Les travaux de Chino Kaori, référence dans l'histoire de l'art et le féminisme, entraînent différents chercheurs à se pencher sur les représentations des identités de genre, notamment pour les rouleaux et illustrations d'œuvres comme le Heiji monogatari, l'Ise monogatari ou ceux de Kanō Motonobu.

157. Des euvres comme Le Dit du Genji ou Si on les échangeait. Le Genji travesti (Torikaebaya monogatari), ou des auteurs comme Natsume Sōseki et Mishima Yukio, sont souvent cités, mais de nombreux textes des ères Meiji et Taishō sont actuellement relus de façon queer. 


\section{Pour une conclusion : de la question féminine au queer en passant par le genre, une révolution épistémologique féministe}

À travers cette esquisse d'une histoire sociale et intellectuelle du $\mathrm{xx}^{\mathrm{e}}$ siècle au Japon, une révolution épistémologique se profile : la critique de la dimension androcentrée de la fabrication des savoirs. Trois dimensions se modifient : les sujets, objets et canaux de diffusion de la connaissance - jusqu'alors presque exclusivement masculins - se féminisent, sans toutefois atteindre la parité en ce début de $\mathrm{XXI}^{\mathrm{e}}$ siècle. Les femmes cessent donc d'être objectivées par des connaissances masculines : devenues sujets de connaissances, leur approche a radicalement renouvelé l'ensemble des sciences sociales ou des sciences dures. Ce cheminement intellectuel est indissociable des mouvements sociaux et féministes, dans un horizon où pratique et théorie se heurtent, se répondent, se rejoignent. La première vague féministe, incarnée par les «bas-bleus » de Seitō, qui prennent la parole pour débattre des droits féminins fondamentaux, correspond aux « recherches sur la question féminine » (fujin mondai kenkyū) qui s'interrogent et tentent de recenser les éléments caractéristiques des expériences sociales des femmes. Ce féminisme proche des idées progressistes des formations politiques socialistes s'infléchit dans l'après-guerre : la deuxième vague féministe s'incarne dans des mouvements féministes multiples, qui prennent leur distance avec le schème de la révolution socialiste. Variée, la réflexion féministe s'interroge sur la sexualité, le travail féminin, la participation politique par exemple, sans cesser de placer les femmes au centre de sa pensée : les « études féminines » (joseigaku) se développent, en particulier dans les années 1970 et 1980. Néanmoins, le concept de « genre » fait imploser un cadre d'analyse fixé uniquement sur les femmes : les visions essentialistes de la différence des sexes éclatent, on développe une approche relationnelle des sexes, on appréhende les relations sociales entre les sexes comme un rapport de pouvoir et on imbrique le genre dans d'autres rapports de pouvoir qui traversent l'ordre social. Il s'agit d'analyser la complexité des deux objets (et sujets) jusqu'alors rarement objets de la production de connaissances : les hommes et les femmes. La perspective des « études de genre » sert une vision féministe, où les universitaires et les différents acteurs et mouvements de la société dialoguent; elle permet également de reconsidérer l'ensemble des minorités sexuelles (gais, lesbiens, bisexuels, transsexuels, transgenres, intersexes), en proposant une déconstruction 
146 Cahiers d'études japonaises n²2

du corps et de la sexualité. Cette focale nouvelle sur le sexe et la sexualité donne lieu aux « études gaies et lesbiennes » (gei/rezubian sutadizu) puis à la « théorie queer »(kuia riron). Moins connues, balbutiantes dans les années 1990, ces recherches se consolident dans les années 2000 et ne cessent de défricher des sujets extrêmement variés, au sein de plusieurs disciplines. Largement ancrées dans une actualité militante, les études gaies et lesbienne comme les études queer savent que leurs racines remontent à la subversion contenue dans les nouvelles recherches dites post-modernes, nées des bouleversements politiques (la décolonisation) et sociétaux (1968 et les mouvements féministes) des années 1970. Dans le cas japonais, on peut ainsi parler de « post-féminisme », ou plutôt de « féminisme de la troisième vague ${ }^{158} \gg$. Cette révolution épistémologique japonaise s'inscrit dans un cadre mondial qui voit la contestation des sciences et des connaissances «blanches » et masculines se concrétiser : le savoir et le pouvoir qu'il implique sont relus à l'aune d'une vision féministe, où les femmes et les autres minorités ne sont plus exclues du processus et de la diffusion des connaissances ${ }^{159}$. Ainsi l'efficacité heuristique des études de genre fait-elle sens. Gageons que l'effectivité future d'une égalité de genre ne fermera pas la porte aux travaux des études de genre, gaies et lesbiennes, et queer : elles constituent des champs de recherche circonscrits au sein-même des disciplines telles que l'histoire, la philosophie, la littérature, la sociologie, le droit, la médecine... La lecture genrée permet ainsi aux chercheurs de toutes disciplines d'aborder d'une façon complexe la totalité des objets jusqu'alors pensés et objectivés par une connaissance androcentrée.

158. Kimura Ryōko (dir.), op. cit., 2009, p. 4.

159. Michèle Le Doeuff, op. cit., 2000, p. 7-18. 


\section{Bibliographie}

\section{Japonais et français}

SOCIÉTÉ FRANCO-JAPONAISE DES ÉTUDES SUR LES FEMMES 日仏女性研究学 会 (dir.), Actes des Recherches collectives franco-japonaises : Pour la comparaison franco-japonaise des études sur les femmes. Sur la nécessité des nouvelles méthodologies comparatives 日仏共同研究報告書女性研究における日仏 比較 新しい比較方法論の必要性をめぐって, Société franco-japonaise des études sur les femmes 日仏女性研究学会, 2002, 131 p.

\section{Japonais}

AkAsugi Yasunobu 赤杉康伸, Tsuchiya Yuki 土屋ゆき, TsuTsui Makiko 筒 井真樹子, Dōsei pātonā, Dōseikon, domesutikku pātonāshippu-hō o shiru tameni 同性パートナー 同性婚・DP法を知るために (Le partenariat homosexuel, connaître la législation du mariage gai et du partenariat), Tōkyō, Shakai hihyōsha 社会批評社, 2004, 228 p.

Collectif, Jendā ga wakaru ジェンダーがわかる (Comprendre le genre), Asabi Shinbun Extra Report and Analysis Special Number, AERA Mook, $\mathrm{n}^{\circ} 78,2002,176 \mathrm{p}$.

EHARA Yumiko 江原由美子, Feminizumu no paradokkusu. Teichaku ni yoru kakusan,フェミニズムのパラドックス定着による拡散 (Les paradoxes du féminisme : sa plasticité au gré de sa définition), Tōkyō, Keisō Shobō 勁草 書房, 2000, 322 p.

EHARA Yumiko 江原由美子, Feminizumu ronsō : nanajūnendaikarakyūjūnendaie フェミニズム論争一70年代から90年代へ (Les débats féministes des années 1970 aux années 1990), Tōkyō, Keisō shobō, 1990, 201 p. 


\section{CIPANGO}

148 Cahiers d'études japonaises n²2

Friedan Betty (trad. Miura Fumiko 三浦富美子), Atarashii josei no sōzō 新 L い女性の創造 (La création d'une nouvelle femme), Tōkyō, Daiwa shobō 大 和書房, 1965, 281 p.

Fushimi Noriaki 伏見憲明, Puraibèto gei raifu posuto ren.airon プライベ 一ト・ゲイ・ライフ ポスト恋愛論 (Ma vie privée gaie : nouvelles théories de l'amour), Tōkyō, Gakuyō shobō 学陽書房, 1991, 277 p.

IDA Kumiko 伊田久美子, «“Baton o watasu” to iu koto. Marukusu shugi feminizumu kara “ohitorisama” e »バトンを渡す」ということ一マル クス主義フェミニズムから「おひとりさま」へ(《Passer le relais » : du féminisme matérialiste au livre La Solitude du troisième âge), Gendai shisō 現代思想 (Revue de la pensée d'aujourd'hui), Ueno Chizuko 上野千鶴子, vol. 17, nº 39, Tōkyō, décembre 2011, 309 p.

IINo Yuriko 飯野由里子, Rezubian de aru 'watashitachi' no sutōrīレズビアン であるくわたしたち>のストーリー (Nos histoires lesbiennes), Seikatsu shoin 生活書院, 2008, 200 p.

IKEDA Kumiko 池田久美子, OKAвE Yoshihiro おかべよしひろ, et al., Sekushuaru mainoriti, dōseiai, seidōitsusei shōgai, intā sekkusu no tōjisha ga kataru ningen no tayōna sei セクシュアルマイノリテイ、同性愛、性同 一性障害、インターセックスの当事者が語る人間の多様な性 (Les minorités sexuelles racontent elles-mêmes l'homosexualité, la transexualité et l'intersexualité, Pour une sexualité humaine variée), Tōkyō, Akashi shoten 明 石書店, 2006 (première édition en 2003), 288 p.

IKEDA Kumiko 池田久美子, Sensei no rezubian sengen - tsunagaru tame no kamuauto先生のレスビアン宣言 つながるためのカムアウト (Manifeste d'une prof lesbienne, un coming out pour communiquer), Kyōto, Kamogawa shuppan かもがわ出版, 1999, 187 p. 
IzUmo Marō 出雲まろう, Manaita no ue no koi まな板のうえの恋 (L'amour au-dessus d'une planche à découper), Tōkyō, JICC shuppankyoku JICC出版 局, 1993, $221 \mathrm{p}$.

KAKEFUDA Hiroko 掛札悠子, Rezubian de aru to iu koto レズビアンである ということ (Être lesbienne), Tōkyō, Kawade shobō shinsha 河出書房新社, $1992,242 \mathrm{p}$.

KAWAGUCHI Kazuya 河口和也, Kuia sutadizu クィア・スタディーズ (Queer studies), Tōkyō, Iwanami shoten 岩波書店, 2003, 130 p.

KAWAHARA Yukari 川原ゆかり, Wakamono bunka to sekushuariti, karuchuraru sutadizu o megutte - jendā kenkyū 若者文化とセクシュアリティカル チュラルスタディーズをめぐって ジェンダー研究 (Culture jeune et sexualité : perspective des études culturelles, dans le journal des études de genre), vol. 2, Ochanomizu joshi daigaku jendā kenkyū sentā nenpō お茶の 水女子大学ジェンダー研究センター年報 (Rapport annuel du Centre d'études de genre de l'université Ochanomizu), mars 1999, p. 113.

Kazama Takashi 風間孝, KaWAguchi Kazuya 河口和也, Dōseiai to iseiai 同 性愛と異性愛 (Homosexualité et hétérosexualité), Tōkyō, Iwanami shinsho 岩波新書, 2010, 212 p.

KimURa Ryōko 木村涼子 (dir.), Jendā to kyōiku ジェンダーと教育 (Genre et éducation), Tōkyō, Nihon tosho sentā 日本図書センター, 2009, 442 p.

MURATA Akiko 村田晶子, Josei mondai gakushū no kenkyū 女性問題学習の研 究 (Mener des recherches sur les études féminines), Tōkyō, Miraisha 未來社, 2006, 262 p.

NAGANo Hiroko 長野ひろ子, Jendāshi o manabu ジェンダー史を学ぶ (Apprendre l'histoire du genre), Tōkyō, Yoshikawa kōbunkan 吉川弘文館, 2006, 212 p. 


\section{CIPANGO}

150 Cahiers d'études japonaises n²2

NAGAYASU Shibun 永易至文, Dōsei pātonā seikatsu dokuhon, dōkyo zeikin hoken kara kaigo shibetsu sōzoku made 同性パートナ一生活読本 同居・税 金・保険から介護・死別・相続まで (Le livre de référence sur la vie en partenariat homosexuel : de la cohabitation, des impôts et de l'assurance sociale jusqu'à la dépendance, le décès et la succession), Tōkyō, Ryokufū shuppan 緑風出版, 2009, 188 p.

OGINo Miho, Jendāka sareru shintai ジェンダー化される身体 (Le corps qui se genre), Tōkyō, Keisō shobō, 2002, 376 p.

Ryū Susumu 竜超, Niji-iro no binkon, LGBT sabaibaru ! Reinbōkarā dewa nuritsubusenai ue to kawaki»虹色の貧困 LGBTサバイバル！レイ ンボーカラーでは塗りつぶせない「飢え」と「渇き」 (La pauvreté Arc-en-ciel. Guide de survie LGBT ! Repeindre la faim et la soif aux couleurs de l'arc-en-ciel), Tōkyō, Sairyūsha 彩流社, 2010, 197 p.

SAITŌ Jun.ichi 斉藤純一, Shinmitsuken no poritikkusu 親密圏のポリテイッ クス (La politique de l'intime), Kyōto, Nakanishiya shuppan ナカニシヤ出 版, 2003, 246 p.

SAWABE Hitomi 沢部仁美, Yuriko, dasuvidāniya 百合子ダスヴェイダーニヤ (Dasvidania Yuriko), Tōkyō, Bungei shunjū 文藝春秋, 1990, 311 p.

Sugiura Ikuko 杉浦郁子, NomiYA Aki 野宮亜紀, ŌE Chizuka 大江千束, Pātonāshippu : seikatsu to seido, kekkon, jijitsukon, dōseikon, パートナーシッ プ・生活と制度一結婚、事実婚、同性婚 (Le partenariat, mode de vie et système ; mariage, concubinage et mariage gai), Tōkyō, Ryokufū shuppan, 2007, 220 p.

Sugryama Takashi 杉山貴士, Kikitai shiritai seiteki mainoriti, tsunagari aeru shakai no tameni 聞きたい知りたい性的マイノリティ つながりあ える社会のために (Pour ceux qui veulent en savoir plus sur les minorités sexuelles, pour une société plus tolérante), Ōsaka, Nihon kikanshi shuppan sentā 日本機関紙出版センター, 2008, 197 p. 
TACHI Kaoru 舘かおる, 《 Jendā gainen no kentō»ジェンダー概念の検討

(Repenser le concept de genre), dans Jendākenkyüジェンダー研究 (Le journal des études de genre), vol. 1, Centre d'études de genre de l'université Ochanomizu お茶の水女子大学ジェンダー研究センター年報, mars 1998, p. 81-95.

Takemura Kazuko 竹村和子 (dir.), «Posuto feminizumu“ポスト”フェミ ニズム (Le « post » féminisme), Tōkyō, Sakuhinsha 作品社, 2003, 226 p.

TAZAKI Hideaki 田崎英明, Jendā/sekushuariti ジェンダー／セクシュアリ ティ (Genre et sexualité), Tōkyō, Iwanami shoten, 2000, 125 p.

UENo Chizuko 上野千鶴子, Shufu ronsōo yomu: zen kiroku 主婦論争を読む: 全記録 (Une documentation complète pour déchiffrer le débat des femmes au foyer), Tōkyō, Keisō shobō, vol. 1 et 2, 1982, 241 p. et 288 p.

VINCENT Keith ヴィンセント・キース，KAZAMA Takashi 風間孝， KaWAGUCHI Kazuya 河口和也, Gei sutadizu ゲイ・スタディーズ (Les études gaies), Tōkyō, Seidosha 青土社, 1997,265 p.

\section{Anglais, français}

Andro-Ueda Makiko, Butel Jean-Michel (dir.), Japon Pluriel 9, Arles, éditions Philippe Picquier, 2014, 520 p.

Bereni Laure, Chauvin Sébastien, Jaunait Alexandre, Revillard Anne, Introduction aux études de genre, Bruxelles, De Boeck, collection « ouvertures politiques », 2012 (deuxième édition), $357 \mathrm{p}$.

Butler Judith, Trouble dans le genre, Paris, La Découverte, 2005, 283 p.

Cadot Yves, Fujiwara Dan, Ōta Tomomi, Scoccimarro Rémi (dir), Japon Pluriel 10, Arles, éditions Philippe Picquier, 2014, 564 p. 


\section{CIPANGO}

152 Cahiers d'études japonaises n²2

Canghuilhem Georges, Études d'histoire et de philosophie des sciences, Paris, Vrin, 1968, 394 p.

Curtis Anderson Gayle, Women's History and Local Community in Postwar Japan, London, New-York, Routledge, 2010, 182 p.

Dales Laura, Feminist Movements in Contemporary Japan, London, New York, Routledge, 2009, 151 p.

Ehara Yumiko, "Feminism's Growing Pains", Japan 2uarterly, vol 47, n 3, 2000, p. 41-48.

Eто Mikiko, “'Gender Problems in Japanese Politics': a Dispute over a SocioCultural Change towards Increasing Equality”, Japanese Journal of Political Science, $\mathrm{n}^{\circ}$ 17, vol. 3, 2016, pp. 365-385.

FLECK Ludwig, Genèse et développement d'un fait scientifique, Paris, Flammarion, collection « champs, science », 2008, 280 p.

Fujimura-Fanselow Kumiko, Transforming Japan: How Feminism and Diversity are Making a Difference, New York, The Feminist Press at the City University of New York, 2011, 560 p.

Fujimura-Fanselow Kumiko, Kameda Atsuko (eds), Japanese Women. New Feminist Perspectives on the Past, Present and Future, New York, The Feminist Press at the City University of New York, 1995, 460 p.

Galan Christian, Lozerand Emmanuel (dir.), La Famille japonaise moderne (1868-1926). Discours et débats, Arles, Picquier, 2011, 666 p.

Germer Andrea, "Feminist History in Japan. National and International Perspectives", Intersections, Gender and the Sexuality in Asia Pacific, vol. 9, Camberra, Australian National University, August 2003, 17 p. 
Iто Satoru, Yanase Ryuta, Coming Out in Japan, Melbourne, TransPacific Press, 2001, 400 p.

KokURYo Sonoko, «L'installation de cours d'études féminines et de centres de documentation sur les femmes au Japon », BIEF, Centre d'études féminines de l'université de Provence, Aix-en-Provence, nº 16, mai 1985, p. 114-120.

Kosofsky-Sedwick Eve, Epistémologie du placard, Paris, éditions Amsterdam, 2008, $257 \mathrm{p}$.

LAURENT Érick, Les Chrysanthèmes roses. Homosexualités masculines dans le Japon contemporain, Paris, Les Belles Lettres, « collection Japon », 2011, 242 p.

Laurent Érick, "Sexuality and Human Rights: An Asian Perspective", in Graupner Helmut, Tahmindjis Phillip (eds), Sexuality and Human Rights, New York, Haworth Press, 2005, pp. 163-225.

Le Doeuff Michèle, Le Sexe du savoir, Paris, Flammarion, collection « champs», 2000, 380 p.

Lévy Christine (dir.), Dossier. Naissance d'une revue féministe au Japon : Seitō (1911-1916), Ebisu, vol. 48, Tōkyō, Maison franco-japonaise, automne-hiver 2012, $224 \mathrm{p}$.

Mackie Vera, Feminism in Modern Japan. Citizenship, Embodiment and Sexuality, Cambridge, Cambridge University Press, 2003, 308 p.

McLelland Mark, Male Homosexuality in Modern Japan: Cultural Myths and Social Realities, London, Routledge Curzon, 2000, 268 p.

McLelland Mark, "The Role of the 'Tojisha' in Current Debates about Sexual Minority Rights in Japan”, Japanese Studies, n 29, vol. 2, 2009, pp. 193-207. En ligne sous : http://ro.uow.edu.au/cgi/viewcontent. cgi article $=1213 \&$ context $=$ artspapers 
154 Cahiers d'études japonaises n²2

McLelland Mark, Dasgupta Romit (eds), Genders, Transgenders and Sexualities in Japan, London, Routledge Curzon, 2005, 218 p.

Minne Samuel, « Le militantisme critique : la reconstruction de l'homosexualité par les scienceshumaines », in CAZIER Jean-Philippe (dir.), L'Objethomosexuel, études, constructions, critiques, Paris, Sils Maria-Vrin, 2009, p. 17-23.

Molony Barbara, Uno Kathleen (dir.), Gendering Modern Japanese History, Cambridge, Harvard University Asia Center, 2005, 607 p.

Osawa Mari, "Government Approaches to Gender Equality in the mid-1990s", Social Science Japan Journal, n ${ }^{\circ}$ 1, vol. 3, 2000, pp. 3-19.

Pflugfelder M. Gregory, Cartographies of Desire: Male-Male Sexuality in Japanese Discourse, 1600-1950, Berkeley, Los Angeles and London, University of California Press, 1999, 399 p.

Robertson Jennifer (ed.), A Companion to the Anthropology of Japan, Oxford, Blackwell, 2008, 544 p.

Suganuma Katsuhiko, "Enduring Voices: Fushimi Noriaki and Kakefuda Hiroko's Continuing Relevance to Japanese Lesbian and Gay Studies and Activism", Intersections: Gender, History and Culture in the Asian Context, $\mathrm{n}^{\circ}$ 14, Nov. 2006, disponible sous http://intersections.anu.edu.au/issue14/ suganuma.htm

Takemura Kazuko, "Feminist Studies/Activities in Japan: Present and Future", Lectora, $\mathrm{n}^{\circ} 16,2010$, p. 13-33, disponible sur dialnet.unirioja.es/descarga/ articulo/3325949.pdf (consulté le 11 janvier 2013)

Vincent, Keith J., "Queering Friendship: Takemura Kazuko", communication présentée le 20 avril 2013 à l'université Emory, dans le cadre d'un colloque intitulé « Sex, Gender, and Society: Rethinking Japanese Feminism », 2013, disponible 
sous http://worldwide-wan.blogspot.fr/2013/05/queering-friendship-takemurakazuko-by.html

Wakita Haruko, Ueno Chizuko, Bouchy Anne (eds), Gender and Japanese History, Ōsaka, Osaka University Press, 1999, 419 p.

Résumé : Les études de genre représentent au Japon une part importante de la production académique actuelle dans plusieurs disciplines, notamment l'histoire, la sociologie et la littérature. Récemment, les recherches estampillées « études gaies et lesbiennes », « études LGBT » ou «études queer », se sont mises en place. En retraçant de façon succincte leur généalogie, on appréhendera clairement le concept de genre, puis son utilisation académique, ainsi que les lectures LGBT et queer qui irriguent certains mouvements féministes et militants. S'interroger sur la fabrication de ces nouveaux savoirs permet de mieux comprendre leur articulation avec les études de genre, elles-mêmes indissociables de l'histoire du féminisme japonais.

Mots-clés : épistémologie, féminisme, genre, queer, LGBT

Abstract: It is a well known fact that, during the last decades, in the wake of the emergence of what is now called gay and lesbian studies, and queer studies, Japan witnessed a flourishing academic production of scholarly works, be they crossdisciplinary, or hailing from the academic fields of history, sociology and literature. As we analyze the history of the elaboration of these new historiographies, we will show how the gender concept as well as the LGBT and queer viewpoints were shaped, and how they are related to the national framework, academic institutions, or social and activist movements. This in turn will bring to light a genealogy between LGBT, queer studies and gender, which is itself linked to the specific context of Japanese feminism.

Keywords: epistemology, feminism, gender, queer, LGBT

$$
\text { キーワード：フェミニズム、ジェンダー、クイア、LGBT }
$$


